\title{
CURSO ENGLISH ONLINE 3D NO MOODLE: UMA PROPOSTA DE ARTEFATO DIGITAL PARA O ENSINO DE INGLÊS COMO LÍNGUA ADICIONAL NA MODALIDADE HÍBRIDA
}

Susana dos Reis ${ }^{1^{*}}$

${ }^{1}$ Universidade Federal de Santa Maria, Santa Maria, RS, Brasil

\begin{abstract}
Resumo
Estudos prévios discutem modelos/frameworks para orientar o desenvolvimento de materiais didáticos para o ensino de inglês como língua adicional na área de Linguística Aplicada. Por outro lado, percebemos ainda a necessidade de melhor estabelecer diretrizes para orientar o desenvolvimento de recursos digitais, já que os modelos existentes raramente descrevem os procedimentos deste processo. Para isso, o objetivo deste artigo é descrever um modelo para dar suporte ao desenvolvimento de artefatos digitais, tendo por base uma perspectiva sociocultural para o ensino de línguas, bem como incluindo e implementando em seu design a pedagogia de gêneros e de multiletramentos. Para ilustrar o Modelo Cíclico de Desenvolvimento de Artefatos Digitais (MoDE), apresento o English Online 3D e destaco as fases que envolvem o design de materiais digitais, as quais são: (1)Análise, (2)Planejamento, (3)Design da interface, (4)Testagem do protótipo, (5)(Re)design, (6) Aplicação e (7) Avaliação. Palavras-Chave: English Online 3D; Materiais Didáticos Digitais; Design; Curso Online; Moodle
\end{abstract}

\section{ENGLISH ONLINE 3D ON MOODLE: A PROPOSAL OF DIGITAL TEACHING MATERIAL TO TEACH ENGLISH AS AN ADDITIONAL LANGUAGE IN A BLENDED MODALITY}

\begin{abstract}
Previous studies have discussed the use and development of digital teaching material to English as an additional language in the field of Applied Linguistics. On the other hand, there is yet a need to describe or
\end{abstract}

\footnotetext{
“É professora associada, no Curso de Letras-Inglês, pesquisadora e docente no Programa de Pós-Graduação Mestrado Profissional de Tecnologias em Rede, na UFSM. Líder do GRPesq/CNPq NUPEAD (Núcleo de Pesquisa, Ensino e Aprendizagem de Línguas a Distância) e idealizadora e coordenadora do Laboratório de Ensino e Aprendizagem de Línguas Online (LabEon), bem como dos cursos de inglês English Online 3D e ReSPOnD. Atualmente atua como coordenadora substituta do Programa de Mestrado Profissional em Tecnologias Educacionais em Rede/PPGTER/UFSM. Desenvolve atividade de ensino, pesquisa e extensão em sua instituição, na área de Linguística Aplicada, sobre ensino de línguas e tecnologias digitais, produção de materiais didáticos digitais, games educativos e, formação inicial e continuada de professores para as modalidades híbridas e a distância. E-mail: susana.reis@ufsm.br ORCID: https://orcid.org/0000-0003-1697-2237.
} 
to establish guidelines to the development of digital material, since mainly the frameworks proposed in our field rarely describe the procedures that involve this process. The article aims at describing a model to support the digital teaching material development, based on a sociocultural view of language teaching, as well as to integrate and to implement the genre pedagogy and the multiliteracies approach into the design. To illustrate this model, it presents the English Online 3D - an online course for teaching basic English, elaborated to be used in a blended modality. The results exemplify the eight steps implemented into the design of the digital teaching material that are (1)Analysis, (2) Plan, (3)Design of interface, (5) Test the prototype, (6) (Re)design, (7) Apply, and (8) Evaluate.

Keywords: Model; Digital teaching material; Design; Online English Course; Moodle 
Introdução

Estudos prévios sobre gestão e o desenvolvimento de recursos digitais para o ensino de línguas por meio de tecnologias digitais têm sido foco de investigação há mais de três décadas (COSTA et al., 2020; REIS, 2010; MARTINS; MOREIRA, 2012), conforme podemos observar em publicações em Linguística Aplicada (LA), mais especificamente naquelas que fazem parte da agenda de pesquisa da área de Computer Assisted Language Learning (CALL) ou de Tecnologias digitais no Ensino de Línguas (ALMEIDA; VIEIRA; AMORIM, 2020; PAIVA, 2019; LEFFA et al., 2020; entre outros).

Nesse repertório de estudos, é notável também o interesse de nossos pesquisadores em não apenas planejar e produzir novos recursos para uso em aula de línguas, mas também em testá-los em contextos escolares e/ou acadêmicos, a fim de evidenciar suas potencialidades nos processos de ensino e de aprendizagem de línguas adicionais. No entanto, nos estudos publicados são poucos os que reportam as etapas de desenvolvimento de recursos digitais, ou seja, como materiais didáticos digitais (doravante MDD) são elaborados para uso no ensino.

Em vista disso, surgem alguns questionamentos: Quais são as etapas/fases que envolvem o processo de design de materiais didáticos digitais, especialmente quando o professor não tem experiência com esse processo? Como orientar esse processo de desenvolvimento? Em que medida as abordagens teóricas contemporâneas (de ensino e de aprendizagem de línguas) podem contribuir para o design de materiais digitais? Mais especificamente, como os princípios teóricos da pedagogia de gêneros (ROSE; MARTIN, 2012) e da pedagogia de multiletramentos (COPE; KALANTZIS, 2009; 2015) podem ser implementados no design de MDD?

Tendo por base essas questões norteadoras e com a intenção de contribuir com a área de LA, em 2012, iniciei, na universidade, um projeto de produção de $\mathrm{MDD}^{1}$ para melhor entender o processo de design, já que nos estudos publicados, até aquele momento, não encontrava uma abordagem teórico-metodológica que apresentasse os princípios de elaboração de MDD, nem como orientar a produção de recursos digitais para o ensino de Inglês como língua adicional por meio de tecnologias. No Brasil, atualmente, a área de CALL já tem consolidada em suas pesquisas algumas teorias que fundamentam as investigações (REIS, 2010; LEFFA et al., 2020), porém, como argumentado por Costa et al. (2020, p. 29) em publicação recente, concordamos que ainda é preciso melhorar a descrição sobre os procedimentos metodológicos e as abordagens que fazem parte do processo de design de MDD. Com o propósito de colaborar nessa discussão, neste artigo entendo que é importante definir o que entendo por design, e para isso adoto o conceito de Filatro (2008) como

a ação intencional e sistemática de ensino que envolve o planejamento, o desenvolvimento e aplicação de métodos, técnicas, atividades, materiais, eventos e produtos educacionais em situações didáticas específicas, a 
fim de promover, a partir de princípios de aprendizagem e instruções conhecidas, a aprendizagem humana (FILATRO, 2008, p. 3).

Na definição de Design instrucional, Filatro (2008) destaca a necessidade de um processo sistemático que envolve "o planejamento, o desenvolvimento e aplicação de métodos, técnicas, atividades, materiais", o que nos permite inferir que, se temos a intenção de criar artefatos digitais com vistas a promover a aprendizagem, é imprescindível elucidar também princípios, conceitos e concepções, que fundamentam não só a aprendizagem humana, como também conceitos e teorias que são basilares para orientar o ensino pelo design proposto.

$\mathrm{Na}$ área interdisciplinar de Tecnologias na Educação, estudos prévios têm apresentado frameworks que fundamentam o design de tecnologias ou de materiais, sejam estes no formato de cursos online, aplicativos ou de outros artefatos digitais, integrando em suas propostas diferentes concepções de ensino e de aprendizagem, ou, ainda, propondo estágios primordiais para guiar o processo de construção (ALLEN, 2006; BEHAR, 2009; FILATRO, 2008; GOMES, 2017; GOMES; REIS, 2019; entre outros).

Um modelo/framework ${ }^{2}$ reconhecido e amplamente referenciado, principalmente para instruir a elaboração de cursos a distância, em diversas áreas de conhecimento, é o ADDIE (ALLEN, 2006). Esse acrônimo sintetiza os estágios propostos para o desenvolvimento de cursos, os quais incluem os processos de Análise, Desenho, Desenvolvimento, Implementação e Avaliação do conteúdo. Conforme propôs o autor, essas fases/etapas são essenciais para a elaboração de um protótipo, porém faz-se necessário ter, também, um bom embasamento teóricopedagógico que ofereça suporte à prática de ensino online. Além desse framework, há, ainda, metodologias que orientam o design de produtos tecnológicos que estão em discussão em diversos estudos na área interdisciplinar (BESSA; ARTHAUD, 2018), tais como a metodologia de pesquisa baseada em design (BAUMGARTNER et al., 2002) e as ágeis (Scrum, por exemplo), usadas para direcionar o desenvolvimento de softwares e/ou produtos tecnológicos. A minha experiência com design de MDD, principalmente com a elaboração de cursos híbridos de língua inglesa, levou-me a concluir que esse processo demanda sistematização, bem como o planejamento das ações dos participantes envolvidos, a fim de fomentar a criticidade, a reflexão e a avaliação de cada etapa que subjaz o desenvolvimento do material desenvolvido (MOTTA-ROTH et al., 2000; REIS, 2003; REIS, 2004; REIS et al., 2012; REIS; GOMES, 2014; REIS, 2017; REIS; PLETSCH, 2019).

Tendo em vista descrever as fases que envolvem o design de artefatos digitais ${ }^{3}$, é importante também definir esse conceito. Artefato digital é todo (ou qualquer) recurso digital que possa ser criado com objetivo educacional para proporcionar a mediação dos processos de ensino e de aprendizagem. Entendo que artefatos digitais, no formato de MDD, são aqueles que podem ser acessados e disponibilizados por meio da Internet, em uma plataforma de ensino e de aprendizagem (Moodle, Google Classroom, BlackBoard, KhanAcademy, ClassDojo, entre outros) ou para acesso por meio de algum dispositivo. 
É importante mencionar que há, também, artefatos criados exclusivamente no formato de áudios, vídeos, de animações ou de jogos, que podem ser acessados por outros dispositivos tais como videocassetes, DVD player, bluerays, plataformas digitais (spotify, youtube, entre outros) ou consoles. Os jogos educacionais, preferencialmente os digitais, podem ser incluídos como MDD, principalmente, quando estão conectados a uma atividade proposta em uma plataforma de ensino, ou, quando explorados como um artefato em uma aula híbrida, por exemplo (REIS; GOMES, 2020; GOMES, REIS, 2019).

$\mathrm{Na}$ teoria sociocultural da atividade (ENGESTROM; 2000; COLE, 1996), "um artefato se refere a um aspecto do mundo material (e conceitual) que tenha sido modificado ao longo da história da sua constituição através de ações" (COLE, 1996, p. 117). Em estudos recentes, artefatos também são compreendidos como Recursos Educacionais Abertos (REA) (MALMANN; MAZZARDO, 2020), o que na concepção da Unesco (2012) foi definido como

Os materiais de ensino, aprendizagem e investigação em quaisquer suportes, digitais ou outros, que se situem no domínio público ou que tenham sido divulgados sob licença aberta que permite acesso, uso, adaptação e redistribuição gratuitos por terceiros, mediante nenhuma restrição ou poucas restrições. O licenciamento aberto é construído no âmbito da estrutura existente dos direitos de propriedade intelectual, tais como se encontram definidos por convenções internacionais pertinentes, e respeita a autoria da obra (UNESCO, 2012, p. 1).

Tendo por base essas premissas, neste artigo apresento e descrevo o curso básico de língua inglesa, nomeado como English Online $3 \mathrm{D}^{4}$ (doravante e-3D), o qual foi idealizado por mim e desenvolvido em colaboração com bolsistas e pesquisadores do Laboratório de Ensino e Aprendizagem de Línguas Online (LabEOn), na Universidade Federal de Santa Maria (UFSM). Além disso, exemplifico as diretrizes utilizadas para orientar o processo de elaboração do design do e-3D, a partir do Modelo Cíclico de Desenvolvimento de Artefatos Digitais Educacionais (doravante MoDE), buscando discutir os pressupostos teóricos basilares desse modelo, como uma alternativa para guiar a elaboração de MDD para o ensino online de Inglês como língua adicional.

Ao aplicarmos o MoDE, descrevo o processo de design que envolveu a construção colaborativa do $e-3 D$, já que esse curso se constitui como uma proposta de recurso digital para promover ações de ensino e de aprendizagem de inglês como língua adicional por meio de tecnologias. A concepção que fundamenta o curso é de linguagem como prática social, com base em gêneros e atividades sociais (HALLIDAY, 1978; 1989; MOTTA-ROTH, 2008), em uma abordagem sociocultural de ensino, aliando a essas concepções, os pressupostos da pedagogia de gêneros (ROSE; MARTIN, 2012) e de multiletramentos (COPE; KALANZTIS, 2009; 2015).

Com esses objetivos, na primeira parte deste artigo, apresento os procedimentos metodológicos; após, são discutidos os fundamentos teóricos que 
estão implícitos no curso e-3D e que embasam o MDD e a prática de ensino de línguas realizada por meio dele. Na sequência, são descritos e analisados os resultados que exemplificam as etapas do MoDE, considerando ainda os dados coletados pela última avaliação realizada no curso.

\section{Metodologia: Contexto de investigação, participantes, ferramentas digitais e critérios}

A presente pesquisa foi desenvolvida na UFSM, no LabEOn, como uma ação de pesquisa do GrPesq/CNPq NuPEAD 5 , e adota métodos mistos para desenvolver esse estudo de base qualitativa, exploratória e bibliográfica, experimental e aplicada. Para isso, utilizamos pesquisa ação e a cartografia (MOTTA-ROTH, HENDGES, 2010; PASSOS; BENEVIDES DE BARROS, 2020) para investigar sobre o processo de desenvolvimento de MDD, no formato de cursos online de línguas para uso em atividades de extensão de inglês como língua adicional.

A cartografia como método de pesquisa visa ao acompanhamento de processos imbricados e, devido a isso, tem um forte viés interventivo, portanto, assume o caráter de pesquisa-intervenção (PASSOS; BENEVIDES DE BARROS, 2020). Concomitante com os pressupostos da pesquisa ação participante, a cartografia também entende que pesquisar é intervir na realidade e não apenas representála. Contudo, essa prática de pesquisa não tem foco apenas em uma direção, mas busca atingir direções múltiplas e plurilaterais. Nesse caso, compreendo que todos os participantes envolvidos nesse processo estão implicados. em vista disso, tanto o pesquisador quanto os pesquisados e o campo de investigação sofrem os efeitos durante $\mathrm{o}$ ato de pesquisar.

\subsection{Sobre o LabEOn e os participantes envolvidos}

O LabEOn é um laboratório do curso de Letras, em cujo espaço temos como objetivo promover ações de ensino, pesquisa e extensão, com vistas à formação de professores para atuação nas modalidades híbrida e a distância. Entre as ações de pesquisa está a produção de artefatos digitais para uso nas aulas de línguas oferecidas em diferentes modalidades.

Para participar das atividades do laboratório, envolvemos alunos de graduação em Letras e de pós-graduação, oriundos dos Programas de PósGraduação Mestrado Profissional em Tecnologias Educacionais em Rede (PPGTER) e do Pós-graduação em Letras (PPGLetras), no desenvolvimento de abordagens e diretrizes para o ensino de línguas com tecnologias, na produção de materiais didáticos digitais e no design de artefatos digitais, aplicativos e jogos educacionais que possam contribuir com o ensino de línguas. Nos últimos cinco anos do projeto, contamos com a participação de mais de 10 discentes, bolsistas e colaboradores, que estão na faixa etária entre 18 e 50 anos, os quais se engajaram no laboratório com vistas a entender como se dá o processo de design de recursos digitais para o ensino de línguas para o ensino híbrido e EAD. 
Para isso, ao ingressar no laboratório, os participantes estudam pressupostos teóricos basilares do projeto sobre ensino de línguas mediado por tecnologias, tais como ensino híbrido e educação a distância, publicados na área de Letras e Interdisciplinar. Por meio de atividades de leitura e de pesquisa, conhecem os pressupostos que fundamentam os processos de ensino e de aprendizagem de línguas, e as perspectivas da pedagogia de gêneros e de multiletramentos (ROSE; MARTIN, 2012; COPE; KALANTZIS, 2009; 2015), cujos estudos são basilares para as ações dos projetos em andamento no LabEOn (REIS, 2017).

Além dessas atividades, os participantes realizam avaliação de ferramentas tecnológicas a serem inseridas no material didático ou nos cursos, analisando os aspectos linguísticos, pedagógicos, tecnológicos e de usabilidade, com base em estudos tais como de Rosell-Aguilar (2017), Reis e Gomes (2014). Ao incentivar os participantes ao engajamento pelo aprender fazendo (Learn by doing), contribuímos também para a exploração autônoma de todo e qualquer recurso digital, de acesso gratuito e aberto, que poderá promover o ensino com qualidade, inovador e tecnológico. Desse modo, acredito que os participantes fomentam a sua própria construção de conhecimento, ao mesmo tempo em que buscam ampliar sua fluência tecnológica e letramento digital ao aprender a usar algumas das ferramentas digitais por meio de atividades práticas. São exemplos de recursos explorados no laboratório as ferramentas do Google (Google Drive, docs, planilhas, power point), editores de imagens, áudios e vídeos (canva, screencast, wevideo, obs, podcast, spotify, entre outros), o software Unity e a plataforma Moodle.

\subsection{Instrumentos de pesquisa, critérios de seleção e avaliação de dados}

A coleta inicial de dados de diagnóstico é uma ação comum a toda e qualquer pesquisa desenvolvida no LabEOn, por isso, após esse procedimento, damos seguimento ao planejamento e ao desenvolvimento do material didático, seguindo o Modelo MoDE (REIS, 2020), conforme descrito na Seção 3 deste artigo. Para isso, inicialmente aplicamos questionários diagnósticos, que são disponibilizados online via Google Forms, no site do grupo de pesquisa ou na página principal da universidade. Após o período de coleta, tabulamos, sintetizamos e interpretamos os dados. Nesse processo, recorremos à análise de conteúdo ou estabelecemos categorias com base em estudos prévios, definimos descritores que nos ajudam a identificar os interesses de potenciais alunos para uso do MDD que será planejado e desenvolvido.

Critérios para avaliação dos dados são com base em publicações em LA e na área Interdisciplinar, mais especificamente, são pesquisas que fundamentam a Análise Crítica de Gêneros (MOTTA-ROTH, 2008) e, também, os estudos interdisciplinares tais como sobre Taxonomia de Bloom e o Modelo ARCS (KELLER, 2009). Esses estudos são basilares para avaliar, por exemplo, o engajamento, a motivação dos alunos, a atenção, a relevância, a confiança e satisfação com relação ao material produzido. 
Em nossas pesquisas, interessa-nos entender e avaliar a experiência de aprendizagem proporcionada por meio da resolução dos desafios propostos nos MDD. Ao analisar os dados, consideramos os discursos que emergem, buscando identificá-los e interpretá-los em uma perspectiva crítica. Ao término do desenvolvimento de um novo curso ou de artefato digital, submetemos questionários de avaliação que passam novamente pelos processos de tabulação, síntese, análise e interpretação, considerando os estudos supracitados.

\section{Modelo Cíclico de Design de Artefatos Digitais (MoDE): objetivos, concepção de linguagem e etapas para orientar o processo de elaboração de recursos digitais}

Estudos recentes, tanto na área da Educação quanto na da Linguística, têm apresentado modelos/frameworks para orientar a elaboração de MDD, principalmente, no formato de cursos online (FILATRO, 2008; NEVES, et. al, 2012; GOMES, 2017; entre outros). Na área da Educação, entre os vários modelos já publicados, temos o desenho (design) instrucional aberto (FILATRO, 2008), o qual surgiu a partir do design instrucional.

Esse modelo, proposto por Filatro (2008), enfatiza a importância de considerar o contexto, as tecnologias usadas e o conteúdo ofertado de modo aberto, fixo e contextualizado quando se produz o conteúdo de um curso. De acordo com a autora, o design instrucional aberto considera que os artefatos, aos quais os estudantes têm acesso, deveriam ser criados, refinados e modificados enquanto acontece o processo educacional. Nesse caso, é importante ainda avaliar a interação que acontece entre os atores sociais desse processo (professores e estudantes), enquanto realizam as atividades online.

Em LA recentemente encontramos em publicações os modelos design educacional complexo (FREIRE; DE SÁ, 2020) e o design com gamification (GOMES, 2017). Há ainda outros, mas nos deteremos a esses dois pela afinidade teórica que compartilhamos. O primeiro, baseia-se teoricamente na perspectiva da teoria da complexidade; já o segundo, nos princípios de design de jogos e na perspectiva de ensino de linguagem como prática social. Outros frameworks que são usados como referência em pesquisas interdisciplinares são: a) o design construtivista (NEVES, et al., 2012); b) o modelo de protótipo para o ensino online (LENCASTRE, 2012) e; c) o design gamificado motivacional (SILVA; DUBIELA, 2014).

Pesquisas realizadas no nosso grupo de pesquisa evidenciam que para implementar o design de um material digital, é necessário conceber/reconhecer um modelo para orientar esse processo e planejar minuciosamente as etapas para o desenvolvimento do material. Estudos prévios já orientados permitiram testar oito fases para guiar a construção de um produto tecnológico, seja este no formato de um curso online ou no formato de conteúdos/materiais digitais, que possam ser oferecidos por meio de um aplicativo, plataforma ou pelo uso de recurso educacional aberto. Portanto, ao iniciar o processo de design de material 
digital, sugiro seguir as fases do MoDE, conforme propostas na Figura 1. Para exemplificar cada fase desse framework, descrevo-as na sequência.

Figura 1: Modelo Cíclico de Design de Artefatos Digitais (MoDE)

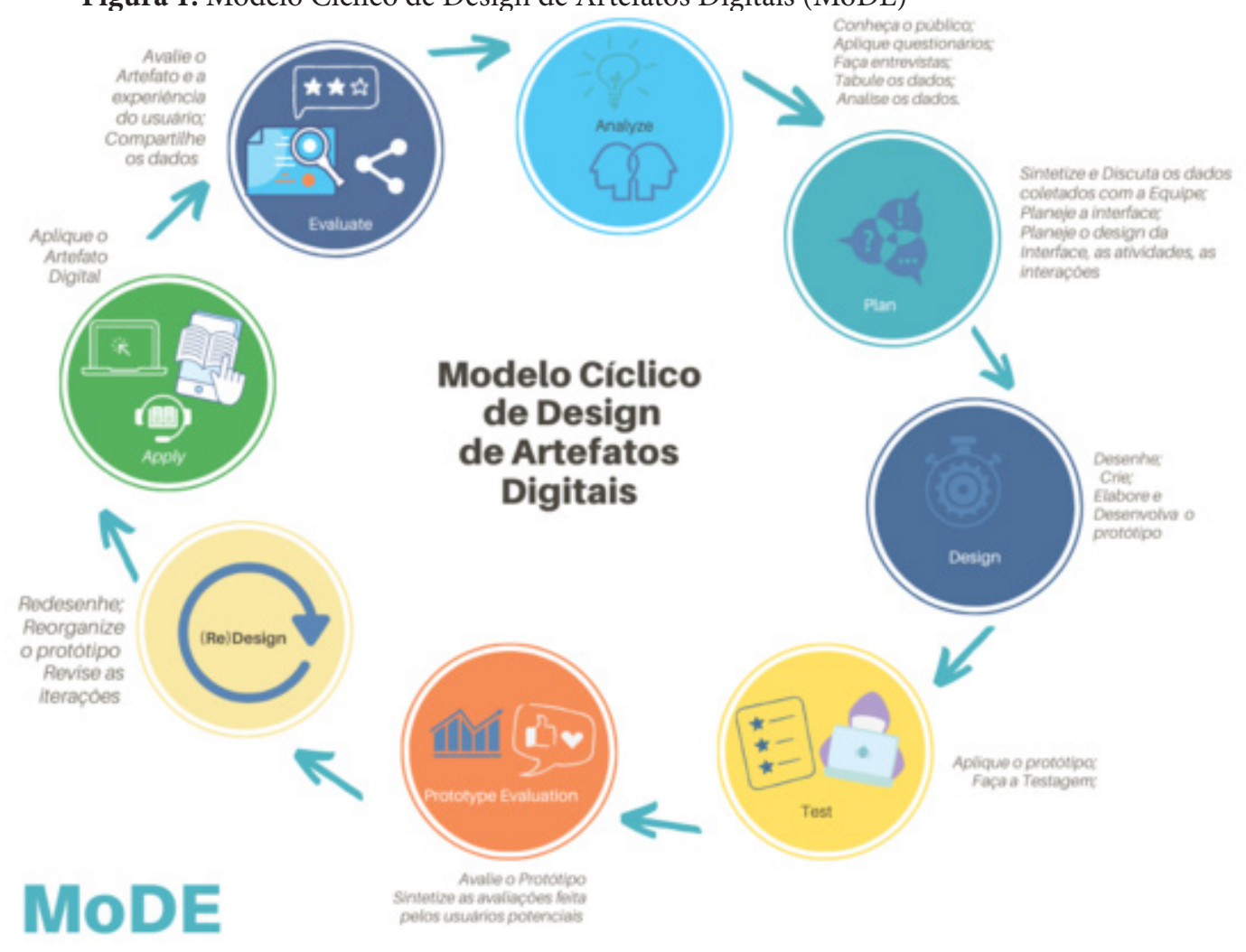

Fonte: Da autora (adaptado de Reis e Gomes (2014); Reis (2020).

Ao iniciar o design de um artefato, é importante na Fase 1 começar pela análise de diagnóstico, identificando os interesses do público-alvo do curso a ser desenhado, para planejar e elaborar o programa, definir cronograma, modalidade e as ferramentas que serão utilizadas no curso. Recomenda-se nessa fase aplicar questionários online (ou impressos), junto ao público desejado para obter informações. Pode-se, ainda, fazer entrevistas in loco ou online. Tão logo a coleta dos dados seja finalizada, é imprescindível sistematizá-los, buscando identificar o perfil e os interesses dos usuários para prosseguir à Fase 2.

A Fase 2 é o momento de planejar o protótipo. No caso do desenvolvimento de um aplicativo, identifica-se também os requisitos iniciais obrigatórios (ou não obrigatórios) que devem constar na ferramenta (SILVA; REIS, 2021). Nesse momento de planejamento da construção do protótipo de um curso (ou de um aplicativo e/ou de conteúdos de um MDD), é recomendado partir dos dados coletados e sistematizados durante a Fase 1. Quanto mais dados obtivermos sobre os usuários potenciais, menos ajustes possivelmente faremos após a aplicação do protótipo. Feito o planejamento, inicia-se a Fase 3 - Design do protótipo. Nesse estágio, incluímos o desenvolvimento tanto da interface do curso/MDD quanto das atividades que permitirão ao usuário explorar o conteúdo do curso/aplicativo. 
A primeira versão do protótipo é para a testagem do artefato digital de, pelo menos, um módulo do material desenvolvido. Isso acontece na Fase 4. Nessa testagem, podemos incluir alunos potenciais como avaliadores ou, ainda, disponibilizar o produto diretamente em contexto de uso, mais especificamente em aulas para efetuar a testagem. Para que o professor como designer perceba as necessidades de ajustes, é essencial que oportunize ao aluno usar o material/ curso. Inicia-se nesse momento um processo de observação e de nova coleta de dados. Se o protótipo é aplicado diretamente em sala de aula, sugere-se que seja comunicado isso aos alunos, pois é um protótipo em avaliação, com a intenção de identificar problemas e, desse modo, minimizar outros futuros.

Essa fase nos conduz para o momento de avaliação do protótipo (Fase 5). Após serão identificados problemas, mas também serão estabelecidos padrões para orientar o design, tanto das atividades quanto do layout do curso. É o momento para encontrar soluções para os problemas elencados. Porém, deve-se dar continuidade ao desenvolvimento do protótipo, por isso é preciso executar o redesign (Fase 6), se necessário. Na metodologia de pesquisa baseada em design, Baumgartner et al. (2012) recomenda que esse estágio se torne iterativo, porém é fundamental considerar nesse processo os dados obtidos pelos usuários potenciais. Com o redesign concluído, aplica-se a primeira versão final do curso/MDD, executando assim a Fase 7, para posteriormente avaliar novamente o produto, e, também, a experiência de ensino; e, por fim, concluir o ciclo com a Fase 8.

\subsection{Desenvolvimento do curso e-3D, integrando os movimentos pedagógicos de aprendizagem por meio de Design, pedagogia de gêneros e de multiletramentos}

Para planejar o design de materiais digitais para o ensino de línguas, uma definição indispensável é a de concepção de linguagem que alicerça a proposta de um material/curso em desenvolvimento. A concepção de linguagem deve orientar não só o planejamento do programa e dos conteúdos, mas também a construção da interface do produto, as interações e as atividades que serão propostas durante o processo de design.

Essa definição deverá influenciar também a escolha dos elementos multimodais (verbais e não verbais) e as ferramentas tecnológicas, que serão usadas no e com o material didático digital proposto. Ao inseri-los no design da interface de um artefato, produzimos significados que trazem consigo ideias, discursos e ideologias que serão disseminados por meio do material produzido.

Considerando essas premissas, nesta primeira seção, discuto as concepções teóricas que dão suporte para o desenvolvimento do design do curso e-3D e que impulsionam as ações de ensino. 


\subsubsection{Sobre o curso e-3D: concepções de linguagem, de ensino e de aprendizagem}

O e-3D surgiu como uma proposta de curso online para ser ministrado na modalidade híbrida, pela necessidade detectada por meio de um questionário diagnóstico aplicado junto aos acadêmicos da UFSM, quanto ao interesse em aprender inglês fazendo uso de tecnologias digitais no ensino (REIS; MATTIELO; LINK, 2013).

O levantamento inicial auxiliou na definição do objetivo do curso e do programa, e, também, no planejamento de atividades que explorassem gêneros multimodais e situações comunicativas/eventos em língua inglesa, por meio de atividades que potencializassem o uso da língua-alvo para comunicar-se. A intenção era oportunizar a simulação de situações possivelmente encontradas em um intercâmbio acadêmico ou cultural, a fim de que os alunos aprendessem a língua pela interação e pelo uso de tecnologias.

Para atingir esse objetivo, nos aliamos à teoria sociocultural, que tem por base os princípios Vygotskianos (1998). Nessa perspectiva, concebe-se que o conhecimento é construído por meio dos resultados das experiências pessoais e subjetivas de uma atividade. Nessa visão, entende-se que a atividade é mediada por signos culturais e artefatos (linguagem, utensílios, tecnologias, meios de comunicação, convenções, entre outras), o que deverá preceder ao conhecimento. No nosso curso, as atividades e as tecnologias utilizadas se tornam artefatos para promover ações, assim como o material didático.

Com isso, à medida que os artefatos mudam, modificam-se também as atividades sociais, as práticas sociais em que os participantes se envolvem, e junto com elas a consciência dos sujeitos envolvidos na experiência. Desse modo, como em um continuum, acreditamos que pela interação, com diferentes artefatos e sujeitos, o processo de conhecimento constrói-se, envolvendo ciclos expansivos de aprendizagem (ENGSTRÖM, 2000).

Nossa meta do curso é que o aluno aprenda a língua de forma contínua, pela interação social e colaboração, por meio de experiências, obtendo desempenho pelo seu envolvimento em práticas autênticas e situadas, fazendo uso da língua em uma perspectiva funcional (HALLIDAY, 1978; 1989). Para isso, propomos o engajamento dos alunos em contextos que o possibilitem explorar gêneros (discursivos, multimodais e digitais), os quais são utilizados como ponto de partida para a modelagem, desconstrução e a compreensão da linguagem, a partir da seleção de exemplares em circulação social para mediar o estudo da língua alvo (REIS, 2017).

Em vista disso, é importante salientar que entendo gêneros como atividades sociais com as quais nos envolvemos ao lermos, ouvirmos, falarmos e escrevermos, ou seja, são instâncias de uso da língua que são constituídas na e pela linguagem (MOTTA-ROTH, 2008). Aliada a essas concepções, recorremos também aos movimentos pedagógicos previstos nos processos de conhecimento de aprendizagem pelo design, propostos por Cope e Kalantiz (2009, p. 187), na perspectiva da pedagogia de multiletramentos. 
Na perspectiva da pedagogia de multiletramentos (COPE; KALANTZIS, 2009; 2015), esses processos representam uma variedade de maneiras e/ou modos de produzir conhecimento. Para os autores (idem, 2009; 2015), os movimentos pedagógicos "são formas de ação, de atividades que o aluno se envolve para aprender e expandir suas possibilidades de aprendizagem" (NEWSLEARNING, 2020). Nessa abordagem, o aluno pode iniciar o seu processo de construção de conhecimento por qualquer um dos movimentos, conforme ilustra a Figura 2.

Figura 2: Knowledge Processes: The pedagogical moves of learning by Design

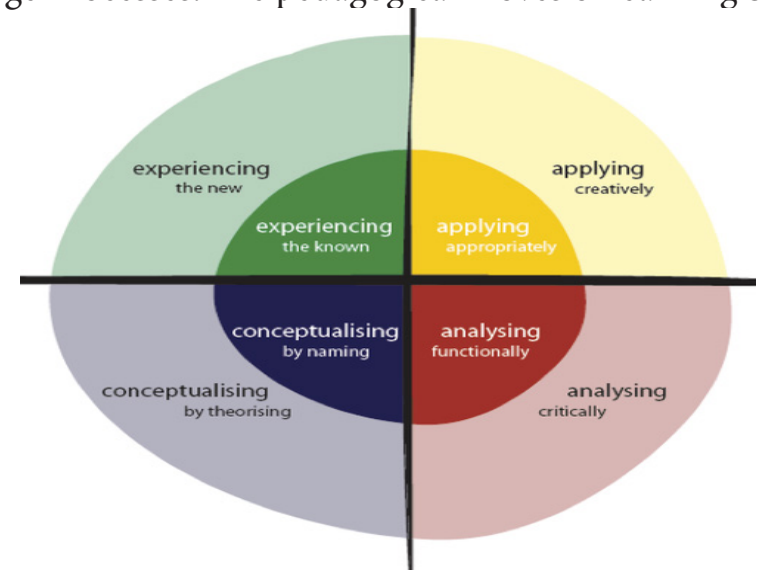

Fonte: Cope e Kalantzis (2009, p. 187).

No e-3D, em práticas de ensino, sugerimos que o aluno seja abordado, primeiramente, pelas experiências que já são conhecidas (experiencing the known) para conduzi-lo à novas experiências (experiencing the new). Nesse primeiro movimento, o/a professor $(\mathrm{a})^{6}$ buscará ativar o conhecimento prévio do(a) aluno(a), ao propor atividades que o ajudem a relembrar vocabulário, experiências, objetos ou coisas. Recomenda-se que o tutor mostre, apresente ou fale sobre tópicos/temas que são conhecidos ou familiares ao aluno(a). Portanto, essa orientação pode acontecer por meio de tarefas que se tornem fáceis do(a) aluno(a) escutar, assistir, ver ou visitar.

Nossa experiência no LabEOn evidenciou que a aplicação dessa abordagem pedagógica não necessita ser implementada apenas no contexto de ensino presencial, ela poderá ser inserida também no design do MDD. Para isso, é preciso planejar tarefas ou conexões com materiais/conteúdos que conduzam o aluno(a) a relembrar e ativar o seu conhecimento prévio, para posteriormente experienciar o novo. Para que o estudante vivencie uma experiência nova de aprendizagem, o/a professor(a) poderá introduzir aquilo que é menos familiar, que faça sentido a ele(a) por possibilitar a experiência pela imersão, por escutar, assistir, ver, visitar e/ou explorar conteúdos que são novos para ele(a).

Nessa fase, as atividades devem provocar o/a estudante a experienciar ainda diferentes textos multimodais que os favoreçam para examinar, conectar, investigar, pesquisar, discutir, gravar, ler, responder (MARCHEZAN; REIS, 2020; BITENCOURT; REIS, 2020). Desse modo, é possível realizar essas ou outras 
atividades que podem ser planejadas para promover o aprender fazendo ou o aprender por meio da ação, oportunizando ao estudante atuar como protagonista, ou seja, permitindo-o realmente atuar no centro do processo de aprendizagem (REIS; PLETSCH, 2019).

Com base nesses pressupostos, as atividades linguísticas planejadas e implementadas no MDD do e-3D contemplam princípios da pedagogia baseada em gêneros e de multiletramentos (ROSE; MARTIN, 2012), sendo nesse contexto a linguagem entendida como um sistema aberto e dinâmico, cuja aprendizagem constrói-se pela interação social. Por meio da interação, entre pares ou com conteúdos, o estudante envolve-se em um processo contínuo de construção de conhecimento, buscando explorar diferentes gêneros e situações comunicativas que são previstas nas missões disponibilizadas no curso.

Em nosso MDD, a fase de modelagem, prevista na pedagogia de gêneros (ROSE; MARTIN, 2012) compreende o processo de desconstrução de um gênero proposto (Deconstruction) e/ou de situações comunicativas, em diferentes níveis de linguagem (do nível fonológico até o do discurso) (Figura 3). Após esse momento, a aprendizagem é ressignificada de forma colaborativa, cooperativa e interativa entre os participantes (joint construction), momento em que os participantes compartilham suas dúvidas, inquietações e descobertas por meio da análise funcional e crítica dos textos em foco, para posteriormente serem capazes de construírem um novo exemplar, em conjunto com seus pares, de modo colaborativo, ou, de modo independentemente (independent construction).

Figura 3: Ciclo de Ensino e Aprendizagem na perspectiva da pedagogia de Gêneros

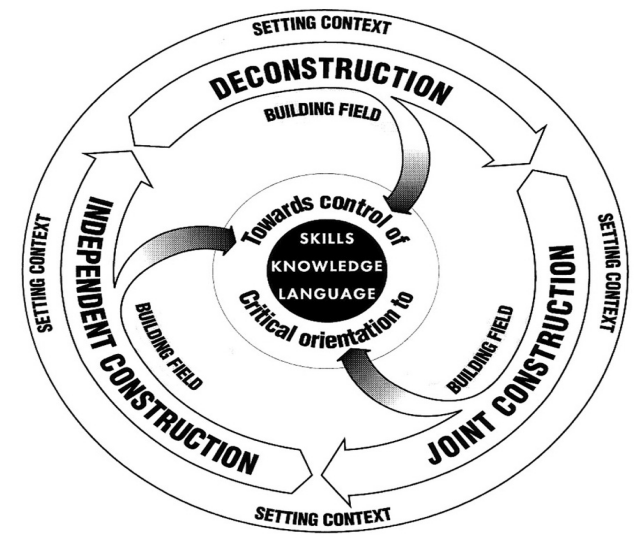

Fonte: Rose e Martin (2012, p.66)

Quando o aluno explora um gênero e o analisa, ele poderá vivenciar diferentes movimentos de aprendizagem, entre eles o de conceitualizar ao nomear (conceptualizing by naming) ou conceitualizar pela teoria (conceptualizing by theorizing) (COPE; KALANTZIS, 2015). Ao explorar um gênero, o aluno estuda a língua alvo pela conceitualização, para isso ele buscará definir termos, elaborar glossários, nomear/etiquetar diagramas, categorizar coisas que gosta e não gosta 
a partir dos textos (verbais e não verbais) com os quais teve contato. Além disso, ao conceitualizar com base em teorias, o aluno arrisca-se, podendo por exemplo criar mapas semânticos, escrever resumos ou trabalhar colaborativamente na construção em conjunto sobre os conceitos e os conteúdos estudados.

Entendo que tanto a fase de conceitualização quanto a de análise funcional (Analysing functionally) e crítica (analysing critically) da pedagogia de multiletramentos fazem parte do momento de desconstrução do gênero em estudo, momento em que por meio de questionamentos ou atividades, podemos direcionar o aluno a entender a organização retórica e os aspectos linguísticos que emergem da situação, do gênero ou evento em estudo. Durante esse movimento, o aluno poderá analisar, comparar, criticar, avaliar, investigar, julgar, interpretar, justificar e explicar o que compreendeu. Desse modo, integramos a pedagogia de gêneros e de multiletramentos, a fim de tornar essa experiência notável e significativa aos alunos envolvidos nesse processo.

Cope e Kalantzis (idem.) sugerem que alguns exemplos de atividades, que podem ser propostas na fase de análise funcional e crítica, entre elas estão: escrever uma síntese, criar um fluxo e/ou diagramas, desenhar e/ou elaborar diagramas/ gráficos/infográficos técnicos, criar roteiros de histórias, fazer modelos, entre outras. As atividades críticas também podem envolver a identificação de lacunas ou de silenciamentos que podem emergir dos textos, a partir da análise dos objetivos, previsão, ou, ainda, da discussão de causas e consequências, sejam estas conduzidas por meio de um debate e de atividades de escrita de textos, tais como a produção de críticas, resenhas, entre outros gêneros de textos. (NEWSLEARNING, 2020)

Por fim, a integração do movimento pedagógico de aplicação apropriada (applying appropriately) e com criatividade (applying creatively) com o momento da construção colaborativa e independente, prevista na pedagogia de Gêneros, favorece que o aluno tenha a oportunidade de trabalhar colaborativamente com seus pares, tanto analisando textos em circulação social quanto orientando-os a produzir um exemplar semelhante, que o motive a aprender através da aplicação.

Ao aplicar apropriadamente o seu conhecimento adquirido ao longo de todo o processo e das experiências de aprendizagem, o estudante poderá escrever, desenhar, vivenciar performances, resolver problemas e, criativamente, usar e explorar seus conhecimentos, podendo desse modo praticar multiletramentos, de modo inovativo, correndo risco, aplicando-os em diferentes contextos, sugerindo e resolvendo novos problemas, traduzindo os conhecimentos adquiridos em novos modos de significados (NEWSLEARNING, 2020).

No e-3D não temos ainda um repertório completo de atividades que aprofundem de modo efetivo todos esses movimentos propostos na pedagogia de multiletramentos, porém buscamos implementá-los no design e, também, nas estratégias pedagógicas de ensino, efetivadas na prática de ensino na modalidade híbrida. Na próxima seção, descrevo como implementamos essas discussões no MDD, utilizando o modelo de design MoDE, para orientar a construção das atividades encontradas no curso online e-3D. 


\section{4. $\mathrm{O}$ curso e-3D como recurso digital para o ensino de Inglês como Língua Adicional para o ensino híbrido}

Para explicar o processo de design do MDD do e-3D, farei inicialmente uma cartografia do processo adotado para a construção do material, considerando nessa descrição algumas tomadas de decisão que foram desdobradas durante o processo de pesquisa, reportando o que aconteceu e modificou-se ao longo da construção, da intervenção e da testagem do protótipo do curso.

Tendo em vista os métodos adotados pela pesquisa ao longo dos últimos cinco anos e, ainda, os pressupostos que fundamentam a construção do curso, retomo neste momento um pequeno histórico sobre o e-3D, com vistas a contextualizar o seu surgimento e descrever as oito fases que envolveram o processo de design até a versão atual.

\subsection{Fases Análise e Planejamento do Curso}

A primeira versão do curso e-3D surgiu em 2013, após a aplicação de um questionário diagnóstico junto à comunidade acadêmica da UFSM. O questionário investigava o interesse dos acadêmicos em realizarem cursos de línguas adicionais por meio de tecnologias digitais. Os resultados obtidos demonstraram o interesse dos alunos em cursos que os preparassem para intercâmbios acadêmicos (REIS; MATTIELLO; LINCK, 2013), haja vista a possibilidade deles conseguirem bolsas de estudos que, na época eram financiadas por agências de fomento e editais, tais como Ciência sem Fronteiras, CAPES e CNPq.

Os dados iniciais coletados nos ajudaram a planejar o protótipo do programa do e-3D, bem como as situações comunicativas, os gêneros e os eventos que um acadêmico se envolve quando realiza um estágio ou intercâmbio acadêmico. A intenção era promover a aprendizagem da língua pelo uso, ao favorecer a inserção dos alunos em situações comunicativas, bem como pela interação e colaboração, princípios estes essenciais e norteadores da prática de ensino de línguas que fundamentam o projeto. Essas definições nos possibilitaram delimitar os tópicos e os aspectos linguísticos a serem abordados no protótipo do curso, bem como a definição da modalidade e das ferramentas.

Ainda, na Fase 2 - Planejamento, escolhemos as ferramentas que seriam usadas tanto no ensino quanto na gestão. Com relação às ferramentas digitais, adotamos os aplicativos do Google, para conduzir e organizar as atividades de gestão do curso e-3D. Nessa etapa, os bolsistas e colaboradores do projeto recorriam a essas ferramentas para trabalharem colaborativamente, tanto na edição do programa (syllabus) quanto na seleção de conteúdos. Nesse momento, planejamos as unidades/missões, selecionamos imagens, conteúdos, vídeos, áudios que poderiam ser inseridos no MDD.

As ferramentas do Google favorecem o trabalho de gestão e de coordenação, principalmente para organizar o trabalho colaborativo, haja vista que por meio do espaço disponibilizado nas nuvens, podemos recorrer aos diversos recursos de 
elaboração de documentos, tendo a possibilidade de escrever colaborativamente os textos e as instruções que serão postados no ambiente virtual de aprendizagem. Além disso, é possível editar os conteúdos no formato de apresentações em power point, elaborar formulários eletrônicos para disponibilizar atividades para uso em aulas ou para avaliação. O uso das ferramentas do Google tornou-se essencial na gestão e na organização de materiais, pois desse modo ao aderirmos ao espaço virtual construímos colaborativamente um banco de arquivos e favorecemos o acesso e a organização às informações para futuras pesquisas.

Com relação à modalidade do curso, inicialmente o interesse era ofertar cursos híbridos e a distância, porém devido à pequena equipe envolvida, optamos pelo design de cursos híbridos, ou seja, cursos aconteceriam presencialmente no laboratório e, também, permitiriam a realização de atividades a distância, por meio de um ambiente virtual de ensino e de aprendizagem. Com essa definição, planejamos os módulos temáticos do curso em níveis 1 e 2, com carga horária de 40 horas, sendo destas 30 horas presenciais no laboratório e 10 horas de atividades a distância.

Como plataforma de ensino e de aprendizagem adotamos o Moodle, por ser um ambiente virtual de código aberto. Também essa plataforma já é institucionalizada na UFSM como ferramenta para viabilizar conteúdos e atividades híbridas para os alunos de graduação e pós-graduação. A partir dessas decisões, iniciamos o planejamento da Interface do protótipo e a elaboração de conteúdos manuseando os recursos básicos do Moodle. Nessa fase, além do programa do curso, definir a paleta de cores a ser utilizada no design gráfico dos materiais, bem como os recursos do Moodle que serão empregados na etapa de Design da Interface, são importantes para orientar o trabalho da equipe envolvida e assim estabelecer a identidade do curso.

\subsection{Fase Design da Interface do protótipo}

A versão protótipo do e-3D foi disponibilizada em 2014 para primeira testagem, e nessa versão optamos por explorar gêneros em circulação social e midiática, com o objetivo de promover atividades e práticas sociais que potencializassem o aluno a aprender fazendo. As atividades linguísticas propostas visavam o uso e a prática da língua-alvo, por meio da resolução de atividades e de problemas que demandavam a ação do aluno, oportunizando a ele o protagonismo no seu processo de aprendizagem.

Para iniciar a Fase 3 - Design da Interface, dos recursos disponíveis no Moodle, recorremos à página web para elaborarmos os conteúdos; espaço este em que combinamos multisemioses para apresentar textos e explicitar tópicos e aspectos linguísticos. Ao explicar determinados aspectos da linguagem, usamos imagens estáticas, vídeos, videoaulas e áudios, além de buscarmos estabelecer conexão com sites externos por meio de links, como Youtube e outras plataformas. A Figura 4 ilustra a tela de abertura do protótipo, criada durante a fase Design da Interface. Nessa versão, o formato do e-3D era apresentado em tópicos, contendo em seu design os recursos multimodais que eram possibilitados no Moodle. 
Figura 4: Tela de Abertura do Curso e-3D, versão 2014 a 2018.

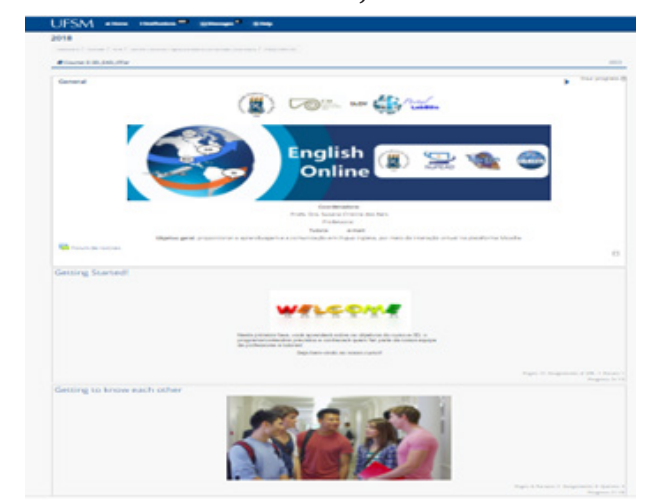

Fonte: Banco de Dados LabEON.

Exemplos de atividades incluídas neste protótipo foram: leitura e elaboração de perfis sociais e acadêmicos, a produção e a leitura de e-mails, a leitura de anúncios de objetos, de lugares para alugar/morar, a leitura e a coleta de informações em páginas web de instituições acadêmicas, pessoais ou em sites de notícias, acesso a videoaulas disponíveis online, entre outras. Durante o Design da interface colocamos em prática o que havia sido planejado (Fase 2), por isso incluímos ao máximo os recursos disponíveis no Moodle, evitando apresentar textos no formato em word ou pdf no ambiente virtual.

No MDD os conteúdos do curso são apresentados por páginas web. Estrategicamente recorremos a um avatar, por meio de uma representação visual, para dar instruções ao aluno no curso. $\mathrm{O}$ avatar assume o papel de Eve, apresentada como nossa tutora virtual no e-3D. Nessas páginas, ela é apresentada por meio de uma imagem estática (Figura 5).

Figura 5: Páginas web com conteúdos linguísticos, perfil social e aspectos gramaticais

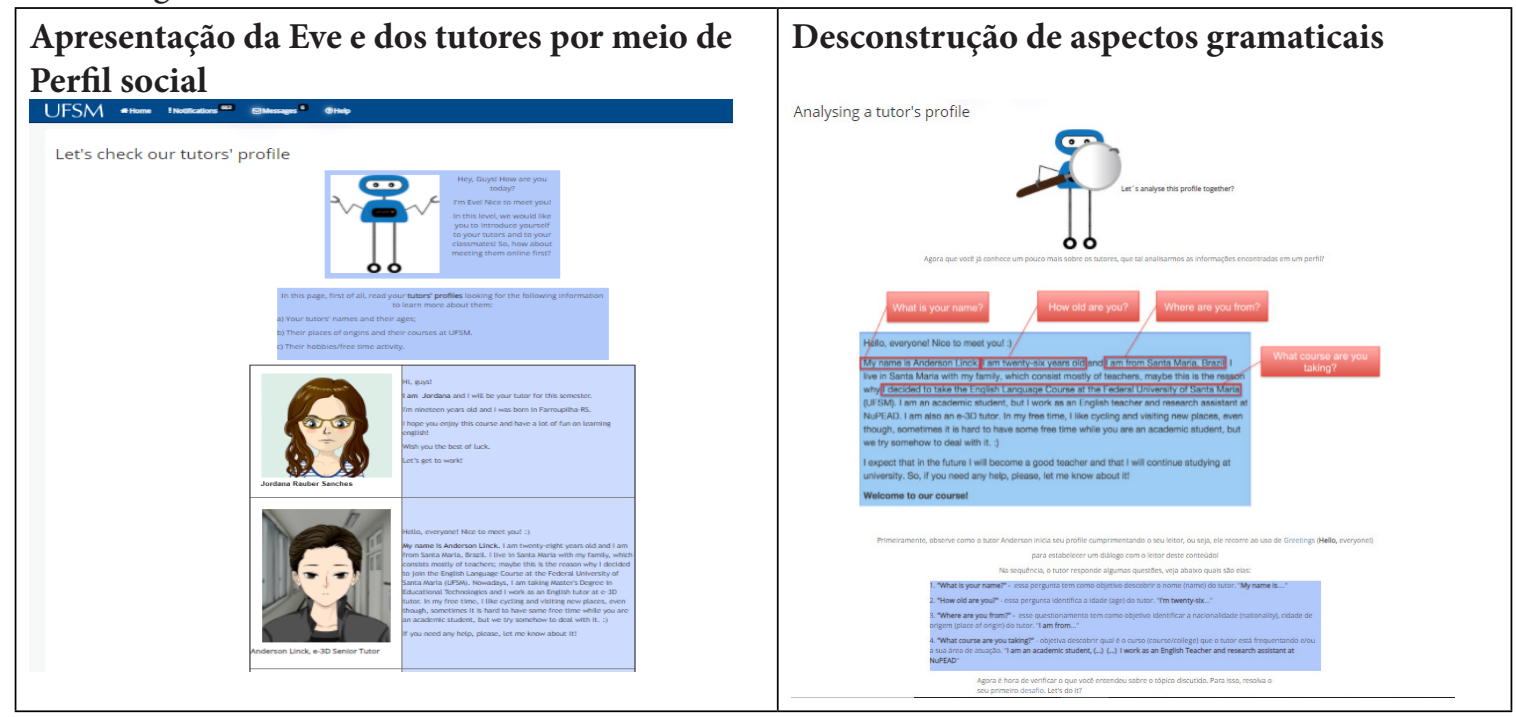

Fonte: Banco de dados do LabEOn, Versão do curso 2018. 
Para apresentar conteúdos em língua inglesa, a combinação de diferentes semioses e de recursos multimodais é essencial, principalmente atentando também para o tipo de fonte, o espaçamento do texto, o alinhamento de textos e imagens, bem como para a combinação de cores usadas e previstas para o design gráfico. A harmonia das informações na página é imprescindível, haja vista a necessidade de chamar a atenção dos alunos ao conteúdo que é acessado e lido na tela. Por isso, recorrer a estratégias que possam contribuir para engajar e motivar o aluno quanto ao conteúdo, é uma forma de garantir que a leitura na tela aconteça e, também, motive o aluno a interagir com o ambiente.

A Figura 5 inclui páginas web com conteúdos linguísticos à disposição dos alunos. O design e organização das informações foram criados durante a fase design da interface do material, momento em que foram elaborados, a partir do programa definido na fase de planejamento. Na primeira unidade, cada tutor é apresentado aos seus alunos por meio de um perfil social, espaço este em que adicionam suas representações visuais pelo seu avatar.

Nos processos de conhecimento, Cope e Kalantzis (2015) sugerem que podemos abordar o conteúdo ou tarefas, levando nossos alunos a experienciar/ relembrar o que já conhecem para, posteriormente, conduzi-los a experienciar aquilo que é novo em relação ao conhecimento linguístico. Os movimentos pedagógicos de aprendizagem por meio do design, ajudam os alunos a envolverem-se nesta experiência. No e-3D, promovemos esses movimentos também no material, por isso, disponibilizamos aos nossos alunos os perfis sociais dos tutores com informações que acreditamos que já eram de conhecimento comum ou compartilhado, considerando suas experiências prévias com ensino de língua adicionais, iniciado no período escolar. Geralmente, perfis apresentam informações tais como nome, lugar de origem, profissão, experiências pessoais, usando processos relacionais (to be, por exemplo), que são aspectos linguísticos comumente discutidos no ensino de línguas na escola.

Ao avaliarmos o material digital produzido no período de 2014 a 2018, notamos que a plataforma Moodle é limitada, o que se torna um empecilho para apresentar conteúdos de modo dinâmico e interativo. Ao efetivar o design gráfico do MDD, a interatividade proporcionada era mínima, pois apenas era permitido imagens estáticas ou conexão com vídeo por meio de links externos. As imagens eram editadas e inseridas no recurso Página Web. A Figura 5, com imagem à direita, mostra a apresentação de conteúdos linguísticos que explicam aspectos gramaticais, recorrendo ao uso de cores e destaques na imagem para chamar a atenção do aluno. Outra possibilidade de apresentação do conteúdo é pelo uso de videoaula, recurso esse pouco explorado nessa versão em função da falta de recursos humanos aptos para elaborar esse tipo de material.

Um material didático digital interativo precisa apresentar uma boa combinação de recursos multimodais, incluindo múltiplas semioses (vídeos, áudios, animações, imagens estáticas, jogos) que poderão ser incluídos nas páginas $h t m l$, java ou em outros formatos. Nesse sentido, é primordial o MDD oportunizar a interação e a interatividade, a fim de provocar o aluno à produção 
e à ação, assim favorecendo a tomada de decisões, a busca pela solução dos problemas propostos, ao se tornar ativo e protagonista de sua aprendizagem.

Portanto, ao elaborar um MDD, é importante lembrar que todo o texto é multimodal por natureza, ou seja, de acordo com Kress e Van Leeuwen (2012), a integração e a interação de diferentes modos semióticos em um mesmo texto contribuem para a existência de um texto multimodal. Ao definirmos o layout de um texto em um MDD, não só escolhemos a fonte, o seu tamanho, os espaçamentos, as cores e a combinação de recursos verbais e não verbais, mas também, nesse caso recorremos à multimodalidade com a intenção de produzir significados. Essa multimodalidade não é exclusiva de textos não verbais, ela também acontece ao produzirmos textos verbais.

Quando estamos em uma conversa face a face, com amigos ou conhecidos, podemos recorrer às nossas expressões faciais, aos diferentes tipos de entonações da voz, aos gestos e ao toque para articular e comunicar, se assim for necessário. Todos esses modos semióticos, combinados pelo uso da língua-alvo, contribuem para a comunicação, com isso temos textos sendo expressos por meio de diferentes modos e demonstrando a sua multimodalidade. Em vista disso, explorar textos multimodais no MDD, sejam verbais ou não verbais, favorecidos pelo acesso às diferentes situações comunicativas e gêneros, pode ser também uma alternativa para favorecer a prática de multiletramentos e reforçar a importância do aluno aprender a ler, a interpretar, a produzir e a distribuir textos que estão em circulação social, incluindo, neles uma variedade de modos semióticos.

O curso e-3D, desde sua primeira versão, passou por vários (re)designs. Atualmente estamos na sétima edição, em vista disso, ressalto que a fase de (Re) Design é essencial no processo de design de MDD. Cronologicamente, após a primeira edição do curso (feita em 2014), colocamos as unidades do curso em testagem, o que nos conduziu para as etapas de Testagem, Avaliação e (Re)Design.

\subsection{As Fases Testagem e Avaliação do protótipo do MDD}

Para prosseguir para as fases de Aplicação/testagem do protótipo (Fase 4) e avaliação do protótipo do MDD (Fase 5), é necessário concluir o design da interface e das atividades de, pelo menos, uma unidade didática para posteriormente contactar o público alvo e/ou testar com turmas de cursos em andamento. Em vista disso, colocamos o material a disposição dos alunos para que eles o explorem e o avaliem, fazendo sugestões e/ou críticas ao material proposto. Esse momento é essencial para o professor desenvolvedor para que ele possa obter diferentes tipos de feedback do usuário, pois pode-se testar, desde as interações previstas com o material até, inclusive, a visualização e apresentação dos conteúdos, a resolução das imagens, dos vídeos, a compreensão das instruções da tarefa proposta, a organização visual das informações apresentadas na tela, entre outros aspectos.

Portanto, é recomendado, após o período de testagem do curso/MDD, propor questionários avaliativos ou fazer entrevistas com os usuários que avaliaram o protótipo, para que eles possam expor suas opiniões, ações previstas na Fase 5 
- Avaliação do Protótipo. A partir dos registros feitos sobre as potencialidades e os problemas identificados, inicia-se a Fase 6 - (Re)design do MDD, se assim for necessário.

\subsection{Fases (Re)design e Aplicação do MDD}

O redesign do curso e-3D acontece desde 2014, o que comprova a importância dessa fase no processo de design de MDD, pois totalizam, até o presente momento, mais de seis reedições. Em 2019, foram inseridos novos plugins na plataforma Moodle da UFSM, entre eles a possibilidade de criar conteúdos mais interativos pelo uso dos plugins H5P, Level Up e BigBlueBotton (GERVASIO, 2019). Em vista disso, o material passou por um novo redesign considerando as demandas já apontadas por usuários e buscando implementá-las no material existente.

Nas avaliações feitas sobre o e-3D em 2019, com relação ao design das páginas, questionamos os usuários sobre o acesso aos conteúdos e, 50\% deles avaliaram como satisfatório, o que nos conduziu a propor redesign quanto a apresentação do formato do material (Figura 6).

Figura 6: Dados obtidos do Questionário de Avaliação, turma 1, de 2019.

4) Em relação ao Design do curso e-3D no Moodle, quanto ao acesso às páginas de conteúdo

8 respostas

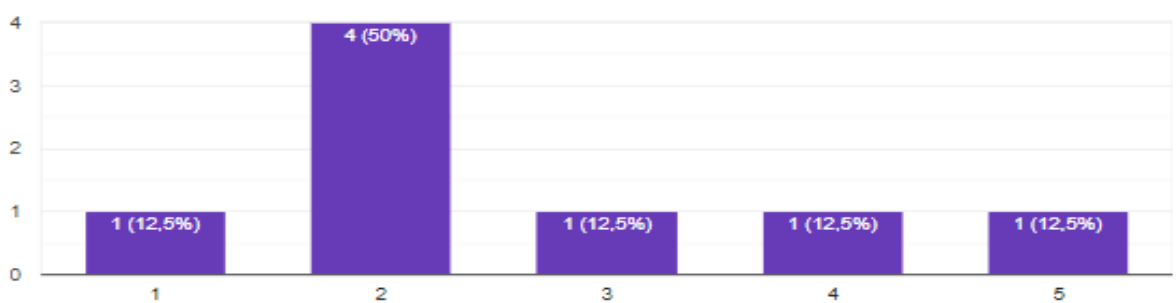

Fonte: Banco de dados do LabEOn - Questionário de avaliação 2019, nível 1.

Para ilustrar alguns dos aspectos reestruturados no material, na Figura 7 apresento a tela de abertura do curso, em que nesse redesign adotamos o formato Grid para dar acesso aos conteúdos. Esse formato torna a apresentação do conteúdo mais dinâmica e interativa, o que pode favorecer o engajamento do aluno, principalmente quando ele está estudando remotamente ou na modalidade a distância. No curso ofertado em 2020, os conteúdos foram liberados conforme o andamento das aulas remotas. Nessa edição, adotamos a modalidade de ensino remoto emergencial e planejamos encontros síncronos e assíncronos para favorecer a interação entre os participantes do curso e os tutores.

É importante enfatizar que, desde 2017, empregamos no curso o uso de estratégias de gamificação (KAPP, 2012; GOMES, 2017; GOMES; REIS, 2019), por isso, as unidades estão nomeadas como fases (Stages), indicando aquelas previstas no material a serem concluídas pelo aluno(a) para que ele avance no curso. Ao final do nível, o aluno pode estar apto a ir para o próximo, desde que 
tenha atingido pontuação mínima com a conclusão dos desafios e, também, avançado em termos de aprendizagem da língua inglesa em estudo.

Figura 7: Tela de abertura do Curso e-3D - versão 2020

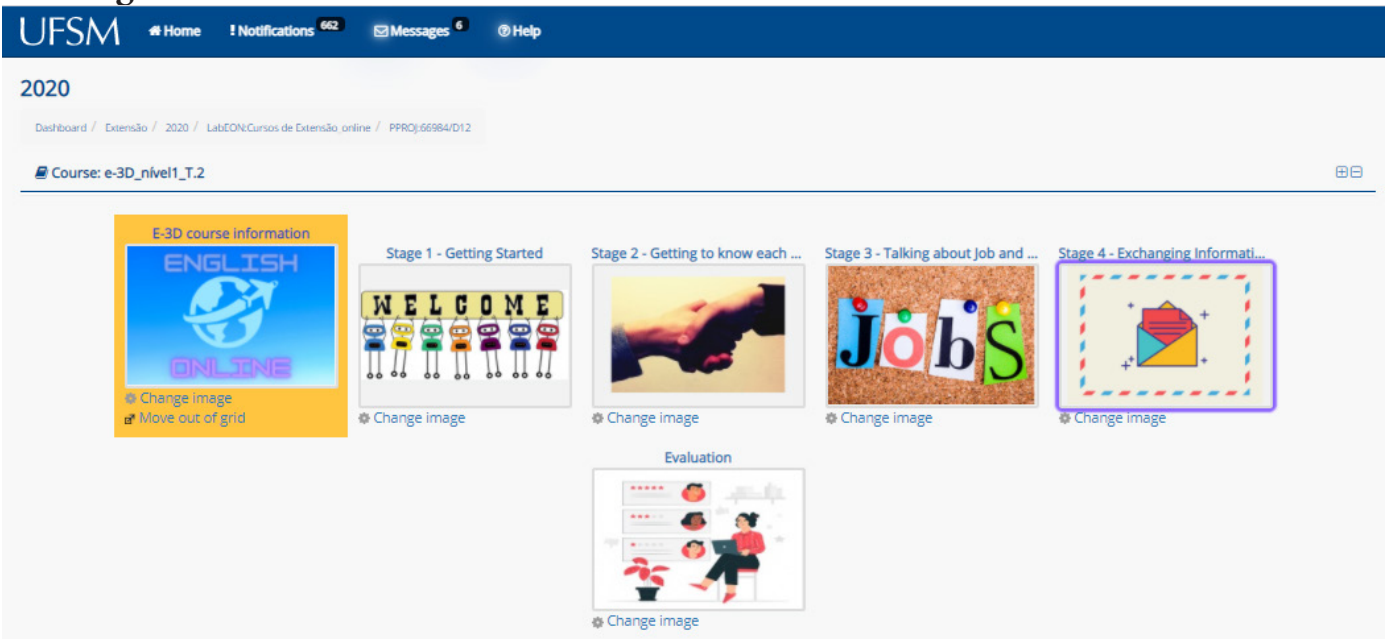

Fonte: Banco de Dados do LabEON - versão 2020.

Outro exemplo de redesign proposto foi na apresentação dos conteúdos utilizando o recurso H5P. Esse acrônimo é abreviação para um conjunto de páginas HTML5 e inclui uma estrutura que permite a construção de conteúdos de código aberto e gratuitos, baseados em JavaScript. Permite criar um material mais responsivo e compatível com dispositivos móveis, o que significa que os usuários terão o mesmo conteúdo rico e interativo em computadores, smartphones e tablets.

Na sétima edição, os conteúdos interativos são favorecidos pelo uso do plugin H5P. Como ilustra a Figura 8, por meio desse recurso o conteúdo é apresentado no formato de slides, espaço em que é possível incluir vídeos (Slide 2, na Figura 8), imagens estáticas ou animadas (Slide 3) e desse modo criar um visual mais dinâmico para sua apresentação. Com isso, consideramos que a inserção do plugin H5P no Moodle tem possibilitado uma variedade de atividades que contribuem para a produção de um MDD que traga em seu design as potencialidades do meio digital.

Figura 8: Quadros com imagens do H5P em formato de slides, incluídos no recurso interativo Course presentation - Versão 2020

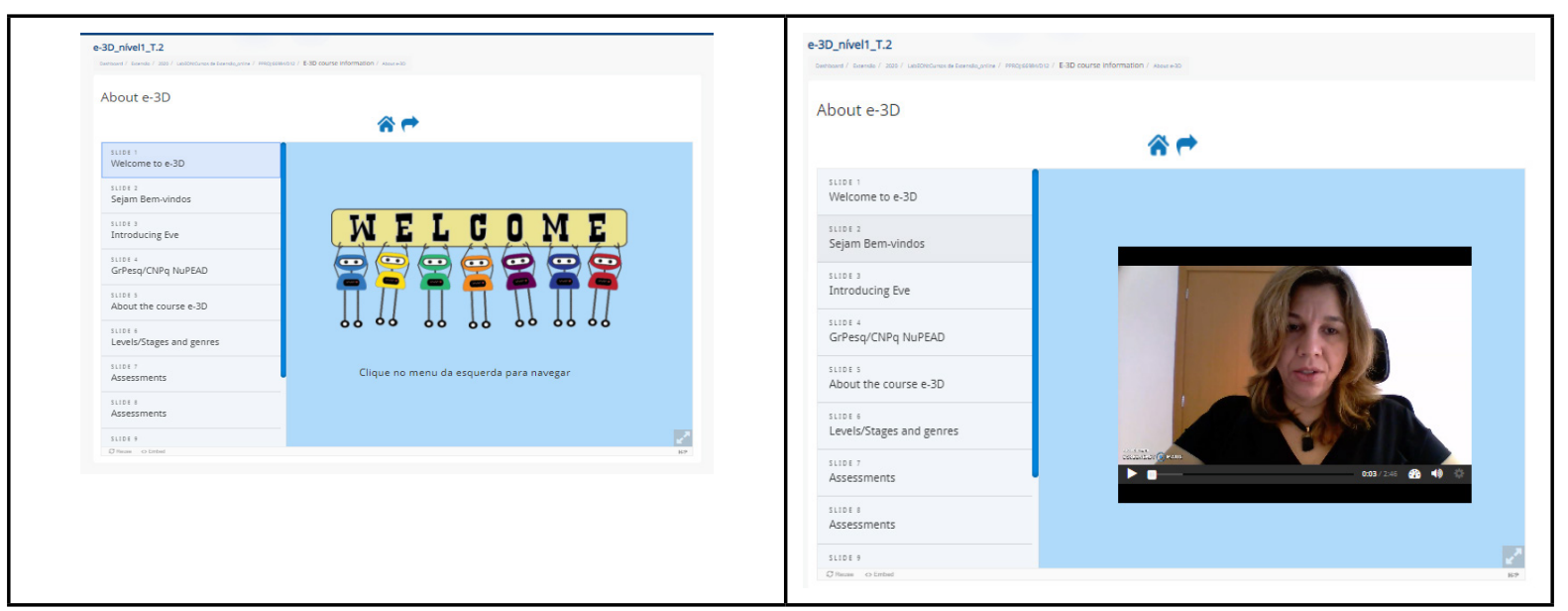




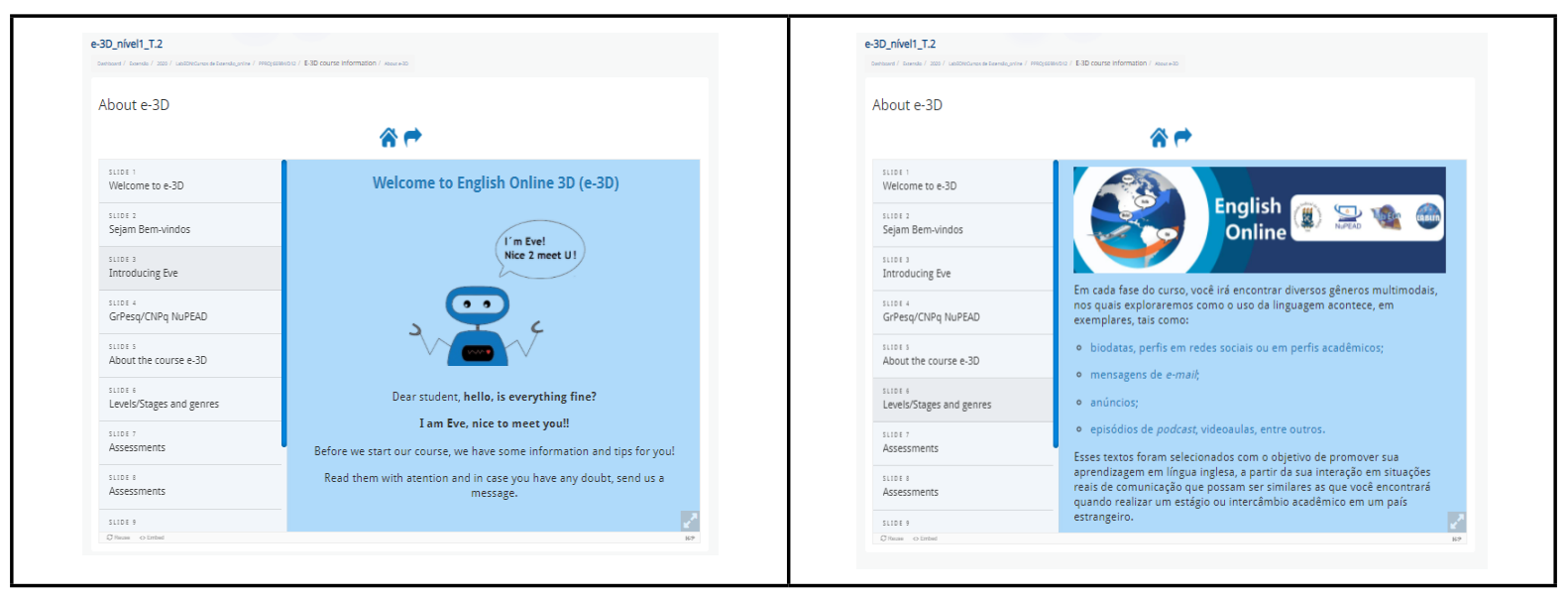

Fonte: Banco de Dados do LabEOn - Apresentação do Curso - Versão 2020.

A avaliação do e-3D em 2019 evidenciou a necessidade de melhorar a aquisição de vocabulário, para isso, recorremos ao H5P para possibilitar que a aprendizagem de novos palavras acontecesse pela associação com imagens ou com situações contextualizadas, a partir de exemplos empregados nos textos utilizados (Figura 9). Para tanto, em atividades práticas buscamos identificar o que o aluno já sabe sobre determinados assuntos/temas, a fim de ativar o seu conhecimento prévio, para posteriormente criar mapas semânticos, relembrar e/ ou aprender novos vocabulários e expressões. Em aulas híbridas e presenciais, essa atividade pode ser feita colaborativamente e de modo compartilhado entre tutores e alunos em aula.

Para ilustrar como os alunos praticam o uso de vocabulários, na Figura 9 mostramos uma atividade de arrastar e soltar (Drag and Drop) elaborada para a prática do vocabulário sobre o tópico Greetings. Nos vários exemplos dados, nos textos disponibilizados nas páginas Reading a self-presentation ou em Greetings around de world, esses vocabulários foram utilizados de modo contextualizados nos perfis ou biodatas encontrados nesta primeira fase do curso. $\mathrm{Na}$ atividade Greetings-vocabulary, os alunos praticam o uso de expressões e dos vocabulários já estudados, estabelecendo por meio dessa atividade a relação entre imagens e o texto para fixar ou relembrar o conteúdo.

Outro aspecto importante a destacar, é que nessa atividade o aluno recebe feedback instantâneo ao concluir a resolução da tarefa. A atividade está configurada para retornar ao aluno sobre os seus acertos e erros, mas não só isso, também caso não atinja o seu objetivo, sugere-se uma nova tentativa e encaminhamento para outras atividades que estão na seção extra activities. No botão check em azul, encontrado na Figura 9, o aluno pode verificar o que acertou ou errou, bem como sua pontuação atingida pela resolução da atividade. 
Figura 9: Atividade Drag and Drop - Greeting Vocabulary - e-3D versão 2020

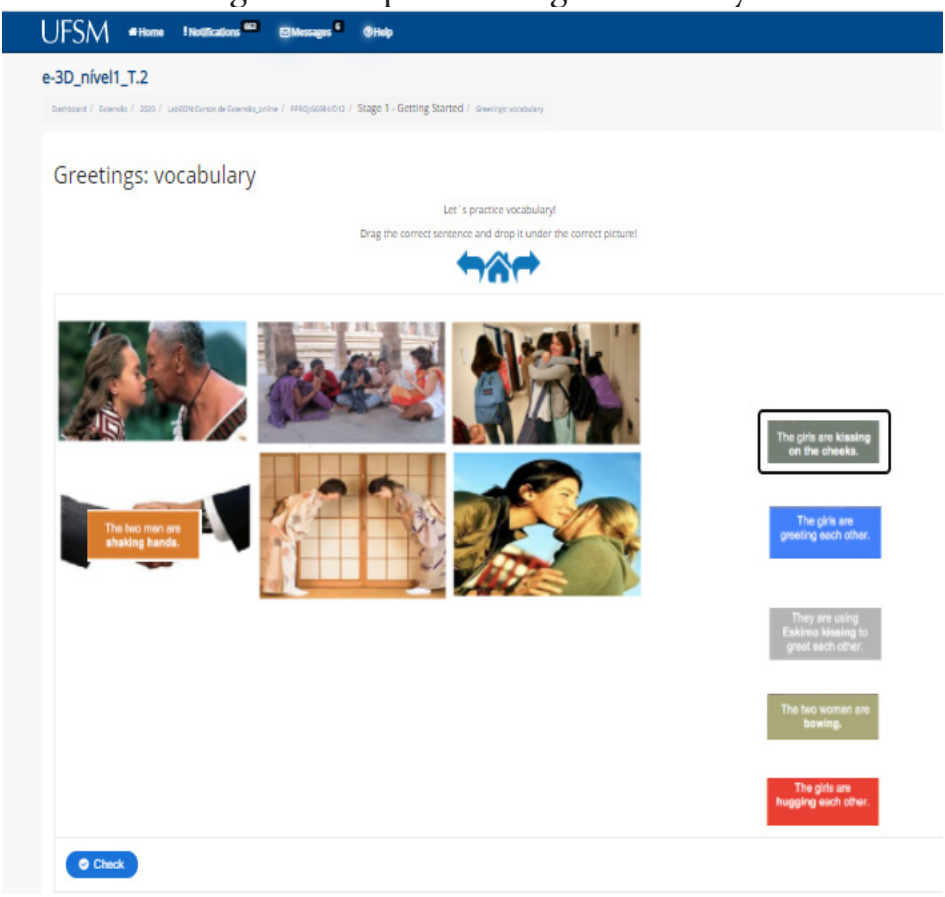

Fonte: Banco de Dados do LabEOn - curso e-3D - versão 2020.

No contexto digital, em aulas remotas é necessário garantir que o aluno ative também seu conhecimento prévio. Para isso, adotamos algumas estratégias e recursos para nos auxiliarem nessa atividade. Na modalidade remota, a abordagem sala de aula invertida (REIS; PLETSCH, 2019) norteia as ações e o acesso dos alunos aos conteúdos. Nessa concepção, concebemos que o aluno deve se tornar o protagonista de sua aprendizagem; portanto, para colocá-lo no centro do processo de aprendizagem, devemos oportunizar a ação e a prática, por meio de conteúdos e de materiais indicados para seu estudo antes da aula síncrona, procurando assisti-los, estudá-los e entendê-los antes do encontro com o tutor.

Os encontros síncronos do curso e-3D são via Google Meet ou pela sala de videoconferência inserida no Moodle, via plugin BigBlueButton. Nesse momento, planejamos atividades que visam a prática do conteúdo pré-estudado. Também, as aulas visam promover a interação e a prática por meio de situações que permitem os alunos colocarem em uso o vocabulário estudado previamente, de modo autônomo. Caso o aluno tenha dificuldades com as atividades anteriores, nesse momento o professor busca também esclarecer dúvidas, incentivar a prática oral e promover trocas e interações entre os participantes. Na Figura 10, mostramos a tela inicial da Fase 1 (stage 1), com os conteúdos linguísticos sendo apresentados pelo recurso H5P utilizado no design do material. Ao clicar em cada um dos ícones, o conteúdo é apresentado. Nesse momento, o aluno já foi instruído no primeiro encontro síncrono sobre como estão organizados os materiais e, com isso, torna-se consciente sobre a organização do curso.

Os conteúdos são liberados conforme o cronograma programado para o curso e previamente apresentado aos alunos na primeira aula síncrona. Abaixo 
do ícone Let's learn, os alunos já foram informados que devem encontrar os conteúdos linguísticos, os quais devem acessar com o objetivo de estudar e aprender o que foi disponibilizado nessa seção; materiais estes que devem ser acessados antes da aula síncrona, fomentando desse modo também a sala de aula invertida (REIS, PLETSCH, 2020).

Figura 8: Abertura do Stage 1 - Getting Started - Versão 2020 - Momento antes da aula

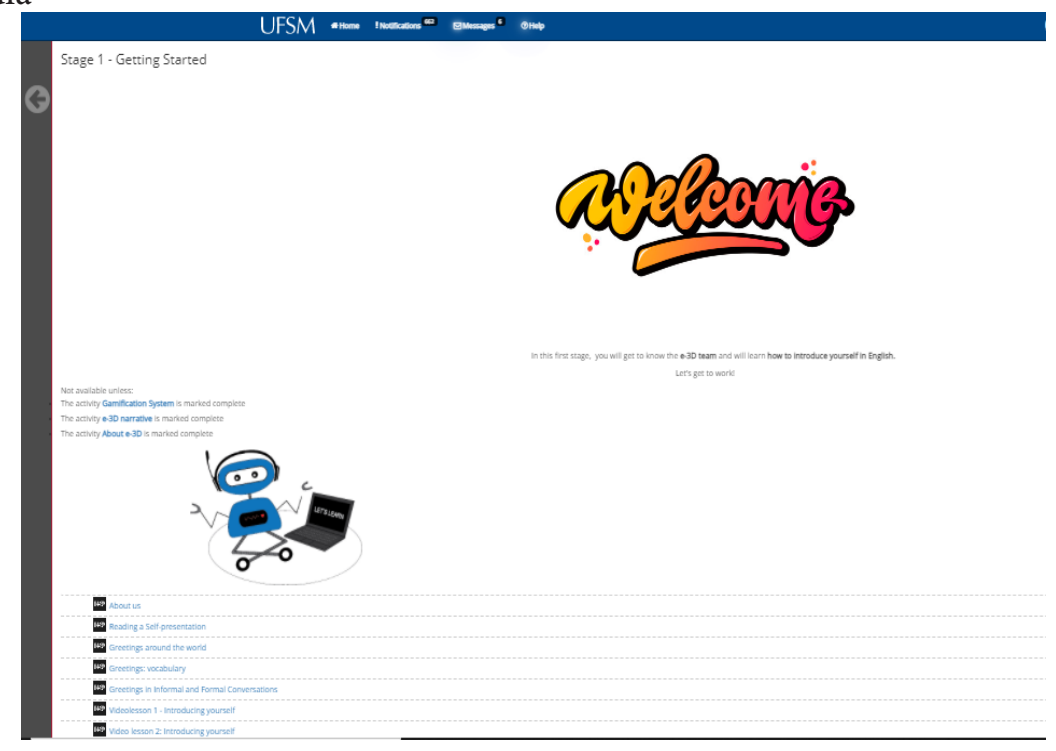

Fonte: Banco de Dados do LabEOn - curso e-3D - versão 2020.

Esses são apenas alguns exemplos de conteúdos e de atividades redesenhadas e incluídas na versão 2020 do curso e-3D, que foram aplicadas na modalidade remota, devido à suspensão das atividades presenciais em nossa instituição. No nosso laboratório já era ativo o uso de materiais mediado por tecnologias e na prática da modalidade híbrida, porém os tutores envolvidos no ensino remoto eram iniciantes com relação ao curso e a modalidade remota emergencial, o que demandou um trabalho colaborativo da coordenação geral e de tutoria, contribuindo desse modo com a formação colaborativa de todos os envolvidos no projeto.

\subsection{Fase Avaliação do Curso}

Após a aplicação do curso e-3D, na versão remota, prosseguimos aos procedimentos de avaliação, assim como temos feitos ao longo dos últimos cinco anos, momento este em que se torna essencial para identificarmos potencialidade, fragilidades e refletirmos não somente sobre o processo de design de MDD, mas também sobre a prática de ensino realizada no período supracitado. Essa avaliação nos conduz para a última etapa do ciclo, que é a etapa de Avaliação. Concluído o ciclo, reinicia-se um novo processo de análise, pela análise diagnóstico aplicada em uma nova turma, com vistas a buscar adequar o material proposto ao novo grupo. 
A etapa de avaliação de um recurso digital é essencial, não apenas para verificar o que deu certo com relação ao material aplicado, mas também para avaliar toda a experiência de ensino. Esses processos iterativos são importantes para que o material didático esteja sempre em processo constante de avaliação, pois desse modo o professor poderá sempre trabalhar com a visão de ensino personalizado, a fim de atender as necessidades e demandas do seu público-alvo.

O Moodle favorece o reaproveitamento dos materiais e a (re)edição, o que facilita esse processo. Além disso, se temos como propósito produzir recursos educacionais abertos, o material deve-se tornar alvo de (re)edição constantemente por seus usuários. Com o e-3D, temos a intenção de torná-lo um curso com código aberto para uso em escolas ou para oferecer cursos gratuitos de língua inglesa, especialmente para alunos que estão em vulnerabilidade social. Atualmente o nosso curso é oferecido apenas no âmbito institucional, com isso o acesso se torna limitado, porém é possível solicitar acesso, caso haja interesse.

Por fim, para avaliar um MDD e sua experiência de ensino, julgo necessário estabelecer critérios, considerando todas as suas peculiaridades e objetivos. No nosso projeto temos utilizado como referências para essa avaliação a Taxonomia de Bloom e o Modelo ARCS (KELLER, 2009), mas também, avaliamos o recurso sob outras dimensões, ou seja, tecnológica, linguística, pedagógica e de usabilidade (REIS; GOMES, 2014; ROSELL-AGUILAR, 2017).

\section{Considerações Finais}

Neste artigo, o objetivo era descrever o MoDE, como um modelo/framework para orientar o design de artefatos digitais, ilustrando suas etapas a partir da produção do curso e-3D, um artefato digital construído no formato de curso online híbrido. É importante salientar que esse modelo, anteriormente nomeado como Ciclo de desenvolvimento de MDD (REIS; GOMES, 2014), foi testado em diferentes estudos prévios realizados em nosso grupo de pesquisa $\mathrm{NuPEAD}^{7}, \mathrm{e}$, ainda, testado e publicado em dissertações que envolviam a produção do materiais didáticos digitais (CECCHIN, 2015; GOMES, 2017; PLETSCH, 2018;LINK, 2018; MARCHEZAN; REIS, 2020; BITENCOURT; REIS, 2020; REIS; PLESTCH, 2019; GERVASIO, 2019; REIS, 2017; REIS; GOMES, 2014; REIS, MATTIELO, LINK, 2013, entre outros), o que reforça a proposta apresentada.

Com isso, evidenciou-se ainda que os pressupostos que fundamentam a concepção de linguagem como prática social e gêneros, e, ainda, a pedagogia de gêneros (ROSE; MARTIN, 2012) e os processos de conhecimento discutidos por Cope e Kalantzis (2015) são viáveis para orientar o processo de desenvolvimento de material didático digital, pois desse modo tornam o processo sistematizado e orientado por concepções teórico-pedagógicas de línguas que estão em foco em estudos da LA. Entendo que os estudos prévios referentes a pedagogia de gêneros (ROSE; MARTIN, 2012) e os processos de conhecimento com base em design, propostos por Cope e Kalantzis (2015) não foram discutidos e implementados tendo como foco o desenvolvimento de material digital, mas sim propostos 
para orientar situações de ensino e de aprendizagem ofertados na modalidade presencial. Desse modo, concluo que o presente estudo contribui para reforçar a importância de integrar tais teorias no design de MDD para o ensino de línguas.

Além desses aspectos, ao planejar um material didático digital, considero que é fundamental ao professor, como designer desse processo, atentar e entender sobre concepções teórico-pedagógicas que irão fundamentar suas escolhas, a fim de fazer escolhas conscientes com relação à combinação das multisemioses que, geralmente, são inseridas em um texto didático, com o objetivo de ensinar. Portanto, durante o processo de design do MDD, é primordial ao professor compreender também sobre os princípios básicos de design gráfico e desse modo fomentar o seu próprio letramento multimodal, pois a combinação de diferentes semioses o ajudará disseminar conteúdos didáticos e torná-los mais atrativos, engajadores e interativos.

Um MDD se torna um artefato notável, quando faz uso de multimodalidades, principalmente àqueles que exploram vídeos, áudios, imagens, com cores e layout organizado e em harmonia, o que poderá favorecer a aprendizagem, já que temos alunos com diferentes estilos de aprendizagem ${ }^{8}$ que acessam o material e buscam aprender com autonomia. Por fim, considero que se a função principal de um MDD é ensinar, para isso ele deverá dialogar com seu leitor, a fim de comunicar e instruí-lo. Nessa interação dialógica, estabelecida entre leitor e autor, por meio do material instrucional, $o(a)$ professor(a) se faz presente também, quando recorre a uma variedade de semioses para promover a aprendizagem significativa e, permite, pelo uso dos recursos inseridos, estabelecer relações com o mundo real, com a vida.

Em síntese, é importante lembrar que os MDD produzidos podem trazer inseridos as concepções de ensino/aprendizagem de seus desenvolvedores, bem como seus discursos e/ou ideologias, que podem ser explicitadas por meio das instruções nos materiais, das escolhas léxico-gramaticais, pelos registros e escolhas verbais ou não verbais da linguagem, implementadas nos artefatos digitais propostos.

\section{Agradecimentos}

Agradeço a colaboração dos discentes do curso de graduação em LetrasInglês e do Programa de Mestrado Profissional em Tecnologias Educacionais em Rede que se envolveram no curso no período de 2013 a 2020 no projeto, os quais buscaram melhorar o material em processo de desenvolvimento, e desse modo contribuíram para a consolidação e a apresentação de um produto melhor qualificado. Também, agradeço pelo financiamento recebido para bolsas de iniciação científica e de extensão pelos fomentos FIPE (2016), FIEX (2018), FAPERGS (2019) e PIBIC CNPQ (2020).

Notas

1. Projeto GAP/CAL/UFSM sob número 031720 .

2. Neste artigo adotarei como sinônimos as palavras modelo, framework ou diretrizes. 
3. Usarei, neste artigo, como sinônimo, as palavras artefato digital, produto tecnológico e recurso digital.

4. curso recebeu este nome em sua versão inicial, a qual foi planejada para ser mediada por ambientes tridimensionais, por meio de mundos virtuais, tais como Opensim, software similar ao Second Life. No entanto, devido a não adaptação do recurso em nossa instituição, a proposta seguiu com esse nome porque incluímos entre os materiais a possibilidade dos alunos explorarem as estratégias de gamificação que fazem parte do MDD, assim como recorrer ao uso de jogos educacionais que são incluídos nas atividades e nos desafios propostos no curso, buscando desse modo integrar uma prática em 3D.

5. O Grpesq/NuPEAD(Núcleo de Pesquisa, Ensino e Aprendizagem de Línguas a Distância) é o grupo de pesquisa no qual desenvolvemos pesquisas que abordam os processos de ensino e aprendizagem de língua em diferentes modalidades (híbrida e EAD), preferencialmente para fomentar atividades de ensino na modalidade a distância, bem como o letramento digital, a formação de professores para o uso de tecnologias e para atuação em EAD e a produção de materiais didáticos digitais para o ensino híbrido e a distância. Mais informações ver em: http://dgp.cnpq.br/ dgp/espelhogrupo/39893.

6. Usarei como sinônimo em alguns momentos do texto a palavra tutor para referirse a ambos os gêneros feminino e masculino.

7. Referências dos trabalhos publicados estão disponíveis em: https://www.ufsm.br/ grupos/nupead/publicacoes.

8. Há alunos que são visuais, cinemáticos, auditivos ou aqueles que combinam vários estilos para aprender.

\section{Referências}

ALLEN, M. Creating Successful e-Learning: A rapid system for Getting It Right First Time, Every Time. São Francisco: Pfeiffer, 2006.

ALMEIDA, P.; VIERA, M.; AMORIN, M. (Org.). Tecnologias Digitais e Formação Docente, $1^{\circ}$ ed., Campinas, São Paulo: Editora Pontes, 2020.

BAUMGARTNER, E. et al. Design-Based Research: An Emerging Paradigm for Educational Inquiry. Educational Researcher, v. 32, n. 1, pp. 5-8. Disponível em: $<$ http://www.designbasedresearch.org/reppubs/DBRC2003.pdf $>$. Acesso em: 26 de Jul, 2019.

BEHAR, P. A. Modelos pedagógicos em educação a distância. Porto Alegre: Artmed, 2009.

BESSA; T.; ARTHAUD, D.D.B. Metodologias ágeis para o desenvolvimento de softwares. Ciência e Sustentabilidade - CeS, v. 4, n. 2, p. 173-213, jul./ dez., 2018. Disponível em: <https://periodicos.ufca.edu.br/ojs/index.php/ cienciasustentabilidade>. Acesso em: Jul. de 2019.

BITENCOURT, D. C.; REIS, S.C. Integração de dispositivos móveis em aulas de língua portuguesa: uma proposta de gestão pedagógica para uso nas escolas. RENOTE, v.18, n.1, 2020. Disponível em: < https://seer.ufrgs.br/renote/article/ view/105986/57832>. Acesso em: Jan de 2021.

CECCHIN, A. S. Práticas de multiletramentos no contexto escolar: investigação de uma abordagem de ensino de produção de narrativa digital. 2015. $168 f$. Dissertação (Mestrado em Tecnologias Educacionais em Rede). Programa de Pós-Graduação em Tecnologias Educacionais em Rede, Universidade Federal de Santa Maria, Santa Maria/RS, 2015. 
COLE, M. Cultural psychology: A once and future discipline. Cambridge, MA: Harvard University Press, 1996.

COPE, B.; KALANTZIS, M. Multiliteracies: new literacies, new learning. Pedagogies: An International Journal, v. 4, n. 3, p. 164-195, 2009.

COPE, B.; KALANTZIS, M. The things you do to know: An Introduction to the Pedagogy of Multiliteracies. In: COPE, B.; KALANTZIS, M. A Pedagogy of Multiliteracies. Learning by Design. pp 1-36, 2015.

COSTA, R.; FIALHO, V.; BEVILAQUA, A, OLIVEIRA, E. 10 anos de Jornada de Elaboração de Materiais, Tecnologia e Aprendizagem de Línguas: Estado da Arte. In:

LEFFA, V.; FIALHO, V.; BEVILAQUA, A; COSTA, R. (Orgs.) Tecnologias e ensino de línguas: uma década de pesquisa em Linguística Aplicada - 1. ed. - Santa Cruz do Sul: EDUNISC, 2020.

ENGESTRÖM, Y. Activity theory as a framework for analyzing and redesigning work. ERGONOMICS, 2000, v. 43, n. 7, p. 960-974. Disponível em <https://courses. ischool.berkeley.edu/i2903/s05/papers/Activity_theory_as_a_framework_for_ analyzing_and_redesigning_work.pdf > . Acesso em: 26 de Jan, 2021.

FILATRO, A. Design instrucional na prática. 1. ed. São Paulo: Pearson Editora, 2008.

FREIRE, M.; DE SÁ, C.F. Design Educacional Complexo: uma proposta para o desenho de cursos complexos. In: LEFFA, V.; FIALHO, V.; BEVILAQUA, A; COSTA, R. (Orgs.) Tecnologias e ensino de línguas: uma década de pesquisa em Linguística Aplicada. 1. ed. Santa Cruz do Sul: EDUNISC, 2020.

GOMES, A. F. Material didático digital e gamification: elaboração de uma proposta de design para o ensino a distância. Dissertação. 2017. (Mestrado Profissional em Tecnologias Educacionais em Rede) - Universidade Federal de Santa Maria, Santa Maria, 2017.

GOMES, A. F.; REIS, S. C. Me-SIGA: Modelo de design com gamification para curso online. In: PAVÃO, A.C.O; ROCHA, K.M.; BERNARDI, G. Tecnologias Educacionais em Rede: Produtos e práticas inovadoras. 1ed, v.2,Santa Maria: FACOS-UFSM, 2019. p. 171-189.

GERVASIO, J. Investigação da customização da plataforma AVA Moodle para uso no ensino de línguas a distância. 2019. 90 Fl. Dissertação. (Mestrado em Tecnologias Educacionais em Rede.) Universidade Federal de Santa Maria. Santa Maria. RS, 2019.

HALLIDAY, M.A.K. Part A. In: HALLIDAY, M.A.K; HASAN, R. (eds). Language, Context and Text: Aspects of language in a social-semiotic perspective. Oxford: Oxford University Press, 1989. p. 1-49.

HALLIDAY, M.A.K. Language as a Social Semiotic. London: Edward Arnold, 1978.

KAPP, K. M. The Gamification of Learning and Instruction: game-based methods and strategies for training and education. Pfeifer, Wiley USA, 2012.

KELLER, John M. Motivational design for learning and performance: The ARCS model approach. Springer Science \& Business Media, 2009.

KRESS, G.; VAN LEEUWEN, T. Multimodal Discourse. The Modes and Media of Contemporary Communication. London: Arnold, 2012.

LEFFA, V.; FIALHO, V.; BEVILAQUA, A; COSTA, R. (Orgs.) Tecnologias e ensino de línguas: uma década de pesquisa em Linguística Aplicada - 1. ed. - Santa Cruz do Sul: EDUNISC, 2020. 
LENCASTRE, J. A. Educação on-line: análise e estratégia para criação de um protótipo. In: BOTTENTUIT JUNIOR, J. B.; COUTINHO, C. P. (Org.). Educação on-line: conceitos, ferramentas e aplicações. 1. ed. Curitiba: CRV, 2012. p. 129-138.

LINCK, A. J. M. Proposta de Diretrizes sobre o Uso e o Desenvolvimento de Jogos Digitais para professores em formação inicial de língua inglesa. 2018, 170f. Dissertação (Mestrado Profissional em Tecnologias Educacionais em Redes). Universidade Federal de Santa Maria, Santa Maria, Rio Grande do Sul, 2018.

MALMANN; E.; MAZZARDO, M. Políticas públicas e práticas para integração de Recursos Educacionais Abertos (REA) na Formação de Professores. ReTER, n.1, v.1, 2020. Disponível em: <https://periodicos.ufsm.br/reter/article/view/61941>. Acesso em: 20 de Jan, 2021.

MARCHEZAN, M; REIS, S.C. LeR Info: uma proposta de material didático digital para o ensino de leitura e produção do gênero multimodal infográfico no Google Classroom. Revista Desenredo,16, n.3, 2020. Disponível em:<http://seer.upf.br/ index.php/rd/article/view/11431>. Acesso em: Jan de 2021.

MARTINS, C.B M,J.; MOREIRA, H. O campo CALL (Computer Assisted Language Learning): Definições, escopo e abrangência. Calidoscópio, v.10, n. 3, p. 247255, set/dez, 2012. Disponível em: <http://www.revistas.unisinos.br/index.php/ calidoscopio/article/view/3254/1280>. Acesso em: 20 de Jan, 2013.

MOTTA-ROTH, D.; CABRAL, R; REIS, S.C; BORTOLUZZI, V. I. Interação \& Motivação em um curso de inglês mediado por computador. Revista Ideias, v. 12, jul/dez, p. 55-59. UFSM, Santa Maria, 2000.

MOTTA-ROTH, D. Análise crítica de gêneros: contribuições para o ensino e a pesquisa da linguagem. D. E. L. T. A., v. 24, n. 2, 2008.

MOTTA-ROTH, D.; HENDGES, G. R. Produção textual na universidade. São Paulo: Parábola editorial, 2010.

NEVES, M. F.; CENTENO, C.; ORTH, M. A.; FRUET, F. S. O.; OTTE, J. Design educacional construtivista: $O$ papel do design como planejamento na educação a distância. In: SIMPÓSIO INTERNACIONAL DE EDUCAÇÃO A DISTÂNCIA (SIED 2012) e ENCONTRO DE PESQUISADORES EM EDUCAÇÃO A DISTÂNCIA (EnPed 2012), São Carlos. Anais... São Carlos: Universidade Federal de São Carlos, 2012.

NEWSLEARNING. Mary Kalantzis and Bill Cope's WebSite. Disponível em:<https://newlearningonline.com/learning-by-design/quick-start $>$.Acesso em: Jan de 2021.

PAIVA, V. L. M. O. Tecnologias digitais no ensino de línguas: passado, presente e futuro. Revista da Abralin, v. 18, n. 1, p. 02-26, 2019.

PASSOS, E; BENEVIDES DE BARROS, R. A cartografia como método de pesquisaintervenção. In: PASSOS, E; KASTRUP, V.; ESCÓSSIA, L. (Org.). Pistas do método da cartografia: Pesquisa-intervenção e produção de subjetividade. Porto Alegre: Sulina, 2020.

REIS, S.C. WebEnglish: Uma proposta de ensino de inglês mediado por computador. Anais... 1st Workshop on Information and Human Language Technology. TIL October, 12th 2003. Disponível em: <http://www.nilc.icmc.usp.br/til/til2003_ English/poster/Rsss35.pdf >. Acesso em: Jan de 2021.

REIS, S.C. A intervenção pedagógica do professor em contextos diferenciados: a oferta de andaimes na aula de inglês presencial e a distância. 2004. 154f. Dissertação (Mestrado em Linguística Aplicada), Instituto de Estudos da Linguagem, Universidade Estadual de Campinas, Campinas: SP, 2004. 
REIS, S.C. Do discurso à prática: Textualização de pesquisas sobre o ensino de inglês mediado por computador. 2010.242 f. Tese (Doutorado em Estudos Linguísticos). Programa de Pós-Graduação em Letras da Universidade Federal de Santa Maria, Santa Maria/RS, 2010.

REIS, S.C.; LINCK, A.J.; MATTIELLO, L English 3D: uma proposta de curso de inglês a distância no projeto LabEOn. In: XVIII CONFERÊNCIA INTERNACIONAL DE INFORMÁTICA NA EDUCAÇÃO (TESE), 2013, Porto Alegre. Anais. Porto Alegre, 2013. p. 353-359.

REIS, S.C. ; GOMES, A. F. Podcasts para o ensino de Língua Inglesa: análise e prática de Letramento Digital. Caleidoscópio, v. 12, n. 3, Set. /Dez., 2014.

REIS, S.C. ; GOMES, A. F. Diretrizes para elaboração de material didático digital complementar com jogos comerciais. In: ALMEIDA, P.; VIERA, M.; AMORIN, M. (Org.). Tecnologias Digitais e Formação Docente, $1^{\circ}$ ed., Campinas, São Paulo: Editora Pontes, 2020.

REIS, S.C. ; PLETSCH, E. Read and Speak English Online Dynamically (ReSPOnD): uma proposta de curso híbrido em língua inglesa na abordagem sala de aula invertida. Linguagem \& Ensino (UCPel), v. 22, 2019.

REIS, S.C. Pesquisa e Ensino sobre Jogos Digitais na Universidade: em busca de diretrizes para o design e uso de jogos em aulas de língua inglesa. In: TOMITCH, L. M.B.; HEBERLE, V. M. (Org.). Perspectivas atuais de aprendizagem e ensino de línguas. 1 ed., Florianópolis: PPGI/UFSC, 2017. p. 15-77.

REIS, S.C. Investigação de diretrizes para orientar a produção de materiais didáticos digitais para cursos online em uma perspectiva sistêmico-funcional com foco em gêneros e multiletramentos. Projeto de Pesquisa. Submetido ao CNPq, 2020.

ROSE, D.; MARTIN, J. R. Learning to write, Reading to learn. UK: Equinox, 2012.

ROSELL-AGUILAR, F. State of the App: A Taxonomy and Framework for Evaluating Language Learning Mobile Applications. CALICO Journal, V. 34, n.2, p. 243258, 2017

SILVA, C. H.; DUBIELA, R. P. Design motivacional no processo de gamificação de conteúdos para objetos de aprendizagem: contribuições do modelo ARCS. In: FADEL, L. M.; ULBRICHT, V. R.; BATISTA, C. R.; VANZIN, T. (Orgs.) Gamificação na educação. São Paulo: Pimenta Cultural, 2014. p. 143-165.

SILVA, J.R. da; REIS, S.C. Guia de Instalação do protótipo SchoolGamify: uma proposta de aplicativo para fomentar a gamificação e a abordagem sala de aula invertida no contexto escolar. Santa Maria: 2021. Relatórios Técnicos do Programa de Pós-Graduação em Tecnologias Educacionais em Rede, v. 3., n.1. Disponível em: <https://www.ufsm.br/cursos/posgraduacao/santa-maria/ppgter/ ppgter-des-21-2021-gui/ $\geq$. Acesso em Fev. de 2021.

UNESCO. Declaração REA de Paris, 2012. Disponível em: http://www.unesco.org/ new/fileadmin/MULTIMEDIA/HQ/CI/CI/pdf/Events/Portuguese_Paris_OER_ Declaration.pdf. Acesso em Jan. de 2021.

VYGOSTKY, L.S. A Formação Social da Mente: o desenvolvimento dos processos psicológicos superiores, 6ª Ed., São Paulo: Martins Fontes, 1998. 